NBER WORKING PAPER SERIES

\title{
INEQUALITIES IN THE TIMES OF A PANDEMIC
}

\author{
Stefanie Stantcheva \\ Working Paper 29657 \\ http://www.nber.org/papers/w29657 \\ NATIONAL BUREAU OF ECONOMIC RESEARCH \\ 1050 Massachusetts Avenue \\ Cambridge, MA 02138 \\ January 2022
}

Prepared for Economic Policy (Special issue on Covid-19). I thank Ferdinand Carre, Martha Fiehn, Jelena Todorovic, and Venance Riblier for outstanding research assistance. This paper would not have been possible without their incredible input and hard work. The views expressed herein are those of the author and do not necessarily reflect the views of the National Bureau of Economic Research.

NBER working papers are circulated for discussion and comment purposes. They have not been peer-reviewed or been subject to the review by the NBER Board of Directors that accompanies official NBER publications.

(C) 2022 by Stefanie Stantcheva. All rights reserved. Short sections of text, not to exceed two paragraphs, may be quoted without explicit permission provided that full credit, including (C) notice, is given to the source. 
Inequalities in the Times of a Pandemic

Stefanie Stantcheva

NBER Working Paper No. 29657

January 2022

JEL No. E24,E3,H20,J24,J6,J81

\section{ABSTRACT}

This paper summarizes the research on some of the major inequalities that have been exacerbated by the COVID-19 pandemic across OECD countries. It reviews findings related to inequalities across the income distribution, sectors and regions, gender, and inequalities in education inputs for children from different socioeconomic backgrounds.

Stefanie Stantcheva

Department of Economics

Littauer Center 232

Harvard University

Cambridge, MA 02138

and NBER

sstantcheva@fas.harvard.edu 


\section{Introduction}

COVID-19 has exacerbated existing inequalities. This paper reviews the evidence to date on how longstanding fractures have been put into sharp relief by the pandemic.

The inequalities described take many forms and express themselves along various dimensions that interact with one another. Across the income distribution, pre-tax income inequalities, consumption and savings, job losses, and opportunities for remote work have evolved very differently. Across genders, and across parents and non-parents, the toll of school closures, lack of child care, and additional housework has been uneven. Across regions, sectors, and occupations, the pandemic has brought vastly different burdens and opportunities.

The paper is organized as follows: The first four sections review the evidence on the evolution of inequalities along several dimensions: across income levels (Section 2); across sectors and regions (Section 3); across genders (Section 4); and across children from different backgrounds (Section 5). Section 6 concludes and the Appendix provides additional materials on each of these topics.

\section{Inequalities across the income distribution}

This section reviews recent work that has investigated the evolution of inequalities across the income distribution in different countries during the pandemic, while also considering remote work opportunities, employment losses, changes in consumption and savings, and the digital divide.

\subsection{Evolution of income inequalities}

The evolution of income inequalities since the start of the pandemic is similar for European and AngloSaxon countries. Accounting for government support during the pandemic through a combination of existing redistributive mechanisms and special measures taken, income inequalities have been reduced in post-tax terms. However, without governmental support, the pandemic would have increased income inequalities, hitting the bottom of the income distribution even harder. Figure 1 shows that, for G7 countries, household incomes have generally increased during the pandemic, while the countries' GDP sharply declined, suggesting important government financial support for households. The lower inequality relative to a counterfactual scenario without government intervention is thus the result of policy responses to the pandemic, which have been able to support low-income households. The pathways for the regressive impact of the pandemic will be covered in the next subsections and include regional disparities, sectoral and occupational composition, and unequal opportunities for remote work.

The effects of policy intervention on measures of inequality such as the Gini index are studied for a number of European countries by Palomino et al. (2020), Almeida et al. (2020), and Clark et al. (2020). O'Donoghue et al. (2020), Brunori et al. (2020), Aspachs et al. (2020) and Li et al. (2020) focus instead on the cases of Ireland, Italy, Spain and Australia, respectively. Table 1 summarizes their findings (see also Appendix A.1). The dynamics of income inequality during the pandemic also suggest that policy responses have more than offset the regressive effect of the virus, but with lagged effects in Europe. Clark et al. (2020) show that in Germany, Spain, France, Italy, and Sweden, inequality - as measured by the shares of income going to different income groups - first widened from January to May 2020, and then decreased back to pre-crisis levels by September 2020.

Overall, statistics pointing to declining income inequality during the pandemic may be misleading. This decrease relies entirely on short-term policy responses to the pandemic outbreak, suggesting that the interventions have been effective to fight inequalities in the short run. However, the direct impact of the pandemic has been regressive and this can persist for at least two reasons. First, at the bottom of the distribution, workers who have been permanently laid off may experience long-term scarring effects of unemployment and human capital depreciation, as well as difficulties finding jobs again. Second, the establishment of remote work as a common practice might widen the gap in the long run, as the subsequent wage premium is unevenly distributed across the income distribution. Some initial insights on the possible long-term consequences of 
the pandemic on the income distribution are uncovered by Angelopoulos et al. (2021) who simulate the evolution of wealth accumulation over the next two decades in the UK. Even under a short recession scenario, where full recovery is reached by 2024, the effect on inequalities will be long-lasting. Indeed, the poorest households, which were more exposed to unemployment shocks, have experienced a decrease in their level of wealth, while high-income households, which were more affected by restrictions on their consumption and less exposed to unemployment, have increased their savings. Consequently, an increase in wealth inequality is likely to persist (Figure A.4).

Table 1: Evolution of Gini coefficients During the PAndemic

\begin{tabular}{|c|c|c|c|}
\hline $\begin{array}{l}\text { Citation } \\
\text { Countries }\end{array}$ & Method & $\begin{array}{l}\text { Without policy } \\
\text { response }\end{array}$ & $\begin{array}{l}\text { With policy response } \\
\text { (Overall effect) }\end{array}$ \\
\hline $\begin{array}{c}\text { Almeida et al. (2020) } \\
\text { EU (27) }\end{array}$ & $\begin{array}{l}\text { Simulating effect } \\
\text { of policies }\end{array}$ & $+3.6 \%$ & $-0.7 \%$ \\
\hline $\begin{array}{l}\text { Aspachs et al. (2020) } \\
\text { Spain }\end{array}$ & $\begin{array}{l}\text { Evolution } \\
\text { over time }\end{array}$ & $\begin{array}{c}+24.4 \% \\
(0.560)\end{array}$ & $\begin{array}{c}-23.21 \% \\
(0.430)\end{array}$ \\
\hline $\begin{array}{l}\text { Brunori et al. (2020) } \\
\text { Italy }\end{array}$ & $\begin{array}{l}\text { Simulating effect } \\
\text { of policies }\end{array}$ & $\begin{array}{l}+0.67 \% \\
(0.3396)\end{array}$ & $\begin{array}{l}-0.67 \% \\
(0.3396)\end{array}$ \\
\hline $\begin{array}{l}\text { Clark et al. }(2020) \\
\text { DE, ES, FR, IT, SE }\end{array}$ & $\begin{array}{l}\text { Evolution } \\
\text { over time }\end{array}$ & $\begin{array}{l}+2.17 \% \\
(0.322)\end{array}$ & $\begin{array}{l}-2.48 \% \\
(0.322)\end{array}$ \\
\hline $\begin{array}{l}\text { Li et al. (2020) } \\
\text { Australia }\end{array}$ & $\begin{array}{l}\text { Comparison market and } \\
\text { post-tax and transfers income }\end{array}$ & $\begin{array}{c}+3.33 \% \\
(0.539)\end{array}$ & $\begin{array}{l}-7.57 \% \\
(0.330)\end{array}$ \\
\hline $\begin{array}{l}\text { O'Donoghue et al. (2020) } \\
\text { Ireland }\end{array}$ & $\begin{array}{l}\text { Comparison market and } \\
\text { post-tax and transfers income }\end{array}$ & $\begin{array}{c}+20.64 \% \\
(0.499)\end{array}$ & $\begin{array}{l}-6.62 \% \\
(0.317)\end{array}$ \\
\hline $\begin{array}{c}\text { Palomino et al. (2020) } \\
\text { EU (29) }\end{array}$ & $\begin{array}{l}\text { Simulating effect } \\
\text { of policies }\end{array}$ & $+3.5 \%$ to $+7.3 \%$ & NA \\
\hline
\end{tabular}

Notes: Figures in parentheses refer to initial level of Gini coefficient, when available.

Almeida et al. (2020) and Brunori et al. (2020) simulate income distribution changes after spring 2020, under scenarios with and without policy response. They estimate the change in Gini coefficient of disposable income, adjusted for household size and composition. Aspachs et al. (2020) compute Gini coefficient of payroll income and labor market related benefits during the first months of the crisis (February 2020-May 2020) and compare it to the values in the same months in 2019. Figures presented in the table refer to April 2020. Clark et al. (2020) estimate the change in Gini coefficient of adjusted disposable income between January and May 2020 and between January and September 2020 using longitudinal survey data from a representative sample of 7,302 respondents. Li et al. (2020) and O'Donoghue et al. (2020) simulate income distribution changes after COVID-19, accounting for the policy response, and estimate the changes in Gini coefficient of market income and of adjusted disposable income, during spring 2020. Palomino et al. (2020) simulate the wage distribution induced by a two month lockdown, with full and partial recovery and estimate the change Gini coefficient under the different scenarios. 
Figure 1: Evolution of household income Per CAPITA AND REAL GDP From 2007-Q1 TO 2020-Q3 IN OECD COUNTRIES

Household income GDP
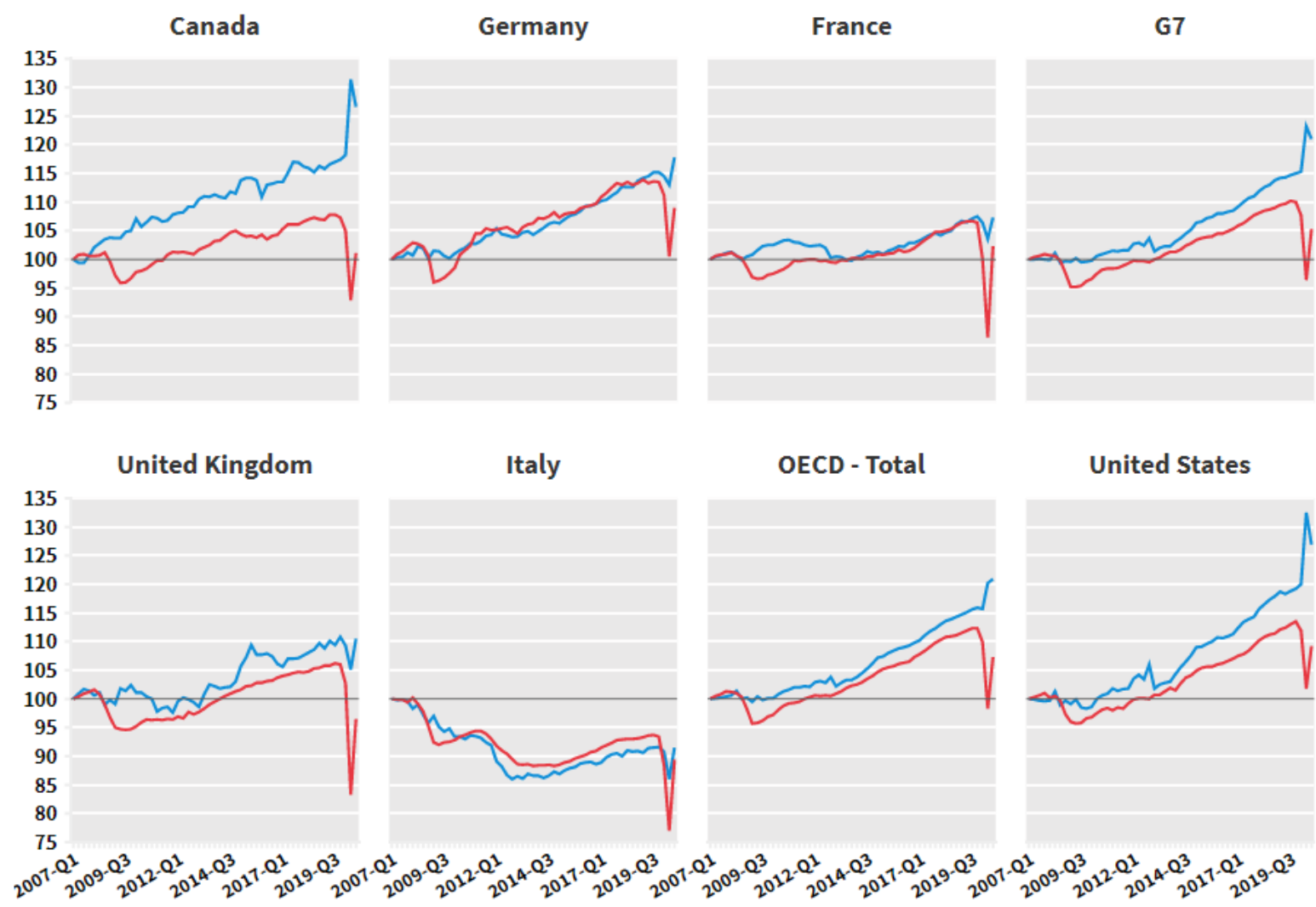

Notes: Figure from OECD (2020), Household dashboard database.

This figure shows the evolution of real household income per capita and real GDP per capita until the third quarter of 2020. The first quarter of 2007 is normalized to 100. 
Figure 2: Loss of InCOME FROM EMPlOyMENT BETWEen 2019-Q2 AND 2020-Q2 IN THE EU, BEFORE AND AFTER GOVERNMENT COMPENSATION, BY INCOME
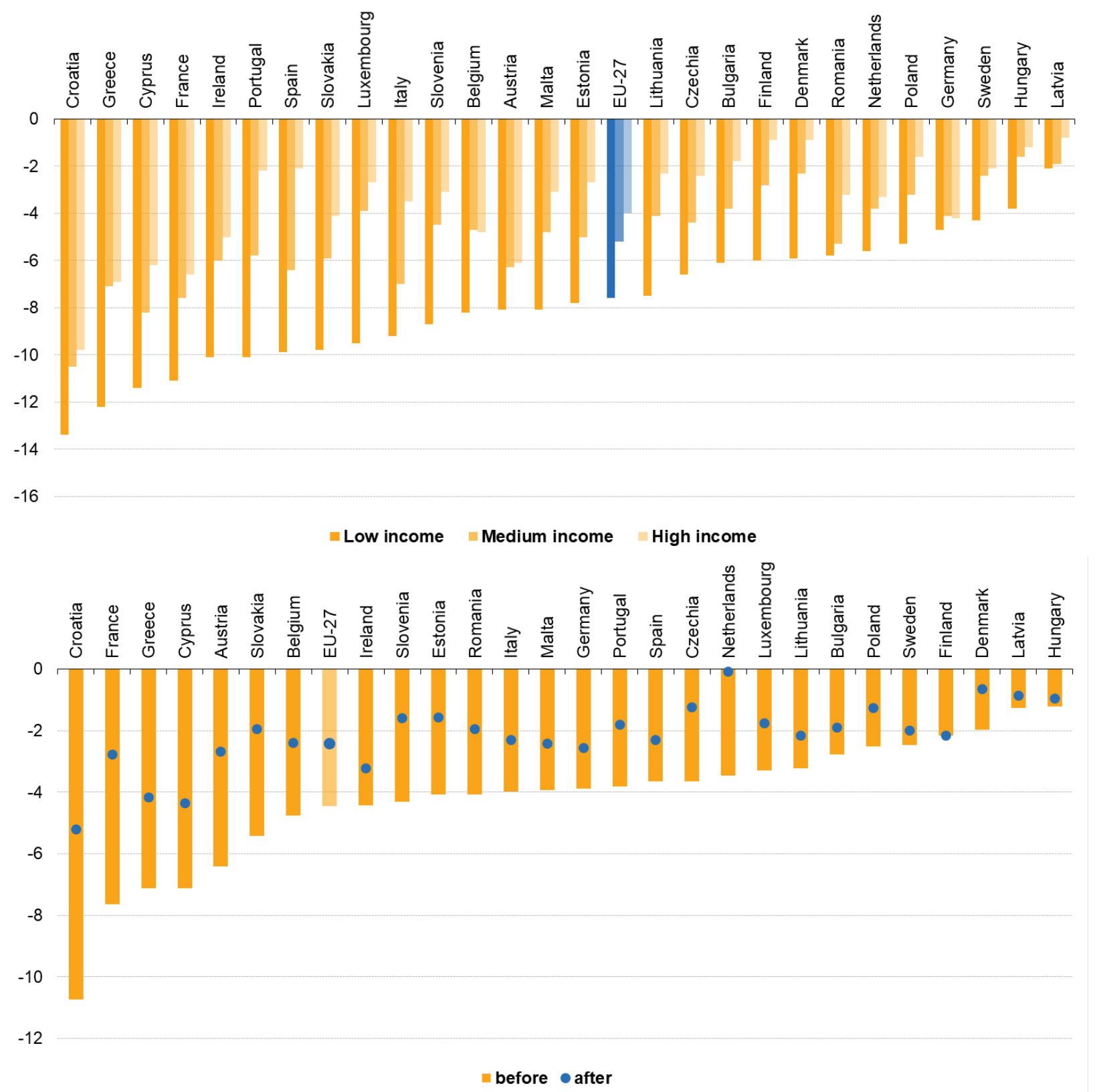

Notes: Figure from Eurostat, Impact of COVID-19 on employment income - advanced estimates (December 2020) In the top figure, each bar represents the percentage employment income loss between the second quarter of 2019 and the second quarter of 2020, by income group. Low-income group refers to the third lowest decile of income distribution, high-income to the third highest and medium to the four intermediate deciles. In the second figure, each bar (dot) represents the percentage employment loss of employees between second quarter of 2019 and second quarter of 2020, before (after) wage compensation. Wage compensation refers to the monetary compensation to employees absent from work due to COVID-19 restrictions that have been provided by European states in response to the pandemic. The changes in income are obtained using the microsimulation model Euromod, calibrated with Eurostat data. 


\subsection{Remote work opportunities as a vector of inequalities}

Remote work has surged dramatically during the pandemic. Research suggests that, while working from home induces a wage premium, the ability to work from home is unevenly distributed across the income distribution. Lower-income employees have fewer opportunities for remote work. In addition, while higherincome employees may, on average, earn a wage premium working from home, the productivity gains of lower-income employees seem much more limited. Thus, the rise and spread of remote work might be a new vector of inequalities, especially if it becomes a norm.

In Europe, Sostero et al. (2020) estimate that $37 \%$ of employees and dependent contractors in the EU in 2018 were in occupations where remote work was possible. This is consistent with Dingel and Neiman (2020), who estimate that $37 \%$ of jobs in the US in 2018 could be done entirely at home. The analysis of Sostero et al. (2020) also suggests that the potential for remote work increases as one moves higher up the wage distribution. Across European countries, $74 \%$ of employees in the top wage quintile can work remotely, compared to only $3 \%$ in the bottom quintile. In the US, the analysis of Bick et al. (2020) confirms that high-income workers have been more able to work from home. In May 2020, the share of employees with 2019 annual income greater than $\$ 100,000$ working remotely was $45.5 \%$ compared to $18.4 \%$ for employees with 2019 annual income below $\$ 50,000$.

This unequal potential for remote work is likely to reinforce existing inequalities. In Germany, Irlacher and Koch (2021) have estimated that, pre-COVID-19 in 2018, workers who were able to work remotely on average received a $12 \%$ wage premium. Bonacini et al. (2021) show that in Italy, an increase in the ability to work from home is correlated with an increase in labor income, thus potentially deepening inequalities between workers who can work remotely and those who cannot. In addition, the wage premium for working from home is higher for workers who already earn more, so that inequalities would increase even among those able to work remotely.

Workers' productivity has been affected heterogeneously by remote work. This seems to be at least partially driven by the sectoral composition at different income levels, as different sectors have different potentials for remote work. It may also be the result of worse working conditions at home for lowerincome households. Based on a representative survey on self-reported productivity conducted in June 2020 in the UK, Etheridge et al. (2020) show that while on average workers report being as productive as one year before the pandemic, low-income workers report being less productive. In particular, workers in the education, administrative, entertainment, and accommodation sectors report significant decreases in their productivity, while those in the financial, insurance, and information technology sectors report increases in their productivity (see Figure A.6).

Remote work may also become a driver of regional inequalities, as its feasibility varies starkly across regions. Irlacher and Koch (2021) find that poorer regions in Germany exhibit a lower share of jobs that can be done remotely. In the UK, De Fraja et al. (2020) have also documented a highly heterogeneous potential for remote work across regions, with the share of residents that can work from home varying between 30 and $60 \%$. These regional imbalances can also partially be seen as the result of the differential potential for remote work across sectors, and the clustering of specific sectors in some regions (see Bonacini et al. (2021) and Figure A.5 for Italy and Crowley and Doran (2020) for Ireland). Appendix A.2 summarizes further findings on remote work. 
Table 2: Potential For Remote WORK is Unequal By InCOME

\begin{tabular}{ccc}
\hline Countries & Citation & $\begin{array}{c}\text { Potential for remote work } \\
\text { is higher at high incomes }\end{array}$ \\
\hline \hline UK & Adams-Prassl et al. (2020c) & $\begin{array}{c}\text { In spring } 2020,60 \% \text { of work tasks } \\
\text { could be done at home for high-earners, } \\
\text { compared with } 20 \% \text { for low-earners. }\end{array}$ \\
\hline US & Bick et al. (2020) & $\begin{array}{c}\text { In May } 2020 \text { the share of high-income remote } \\
\text { workers was } 45.5 \% \text {; for low-income workers it was } 18.4 \% .\end{array}$ \\
IT & Bonacini et al. (2021) & $\begin{array}{r}\text { In } 2018, \text { average labor income for workers with } \\
\text { low remote work potential was } € 24,731, \text { against } \\
€ 27,320 \text { for those with high potential }\end{array}$ \\
\hline EU (27) & Sostero et al. (2020) & $\begin{array}{c}\text { In } 2018,74 \% \text { of high earners could work } \\
\text { remotely, while just } 3 \% \text { of low earners could. }\end{array}$ \\
\hline
\end{tabular}

Notes: In Adams-Prassl et al. (2020c) high-earners refers to households with gross labor income above $£ 70,000$ and low-earners to those with less than $£ 10,000$ in 2019 . The estimate is based on a representative survey of 24,924 respondents. In Bick et al. (2020) high-income households earn more than $\$ 100,000$ in 2019 and low-income households earn less than $\$ 50,000$. The estimate is based on a representative survey of 5,000 respondents. Bonacini et al. (2021) use the index proposed by Barbieri et al. (2020) to measure remote work potential with the Italian Labor Force Survey. Workers with low (high) remote work potential are those below (above) the median value they compute. In Sostero et al. (2020), high- and low-earners refer to top and bottom quintile of wage distribution. Their estimate is based on the European Labor Force Survey.

\subsection{Employment loss}

During the Pandemic. When it comes to the employment loss due to the pandemic, lower-income workers face two countervailing forces. On the one hand, they are more likely to work in "essential" occupations, which suffered less from layoffs or furloughs. On the other hand, they are also more likely to work in occupations with lower potential for remote work or which were more exposed to adverse labor demand shocks.

Overall, the unemployment shocks were heterogeneous across the income distribution, and low-income workers have been more vulnerable to them. In the UK, Piyapromdee and Spittal (2020) show that the likelihood of being laid off or furloughed decreases with higher earnings and wealth. Using data from the UK Household Longitudinal Study, they estimate that in April 2020, 52.7\% of individuals in the bottom quintile of the earnings distribution were either furloughed or fired, compared with just $15.1 \%$ of people in the top quintile. This finding is consistent with those of Adams-Prassl et al. (2020b), who use a representative survey to show that in the UK, from February to March 25, 2020, $12 \%$ of workers earning less than $\$ 20,000$ lost their jobs because of the pandemic, against $5 \%$ of workers earning more than $\$ 40,000$. For Australia, Li et al. (2020) estimate the propensity of dropping out of employment, conditional on being employed in the previous month, by market income quintile. Their results suggest that labor market disruptions peaked in April 2020, when the propensity is estimated at $14.17 \%$ for the bottom quintile against $2.58 \%$ for the top quintile. In June 2020 this propensity was reduced to $1.78 \%$ for the top quintile, while it decreased only to $6.97 \%$ for the bottom quintile. In the US, the fall in employment rates has also been more pronounced for low-income workers. About 37\% of those in the bottom wage quartile lost their jobs between January and April 15, 2020, compared to $14 \%$ of those in the top quartile (see Chetty et al. (2020) and Appendix A.3). For workers in the top wage quartile, the evolution of employment seems to have been V-shaped (see Figure A.7), i.e., their employment has quickly recovered. This is not the case for people at the bottom of the income distribution.

Longer-term effects. Prolonged periods of unemployment are known to be harmful for human capital, 
reducing the likelihood of reintegrating into the labor market (Phelps (1972) and Blanchard and Summers (1986)). Unemployment during the pandemic can become even more challenging to escape, as, in addition to the decline in economic activity, it may come with more domestic work, such as home child-care duties, which can make the search for jobs even more difficult.

These effects on unemployment might not only turn out to be long-lasting, they could also widen the gap between low- and high-wage workers. As highlighted by Tyson and Lund (2021), low-income workers will face higher pressure to reallocate since they are over-represented in occupations with lower potential for remote work and in sectors more adversely hit by the pandemic. Furthermore, the pandemic has also accelerated automation and digitization, and these trends favor more skill-intensive sectors. In a nutshell, the pandemic has increased the supply of low-skilled labor, and the demand for high-skilled labor, thus creating a mismatch. The analysis by Stiglitz (2020) reaches the same conclusion. Modeling the macroeconomic consequences of the uncertainty surrounding the pandemic and the resulting precautionary behavior using US data, the author shows that labor-intensive sectors are less attractive, thus reinforcing automation and inequalities. Moreover, as shown by Pieh et al. (2020), low-income households have suffered greater mental health deterioration, which can compound their difficulties in searching for a job.

Figure 3: Risk of JOb LOSS in Europe BETWEen FIRST AND SECOND QUARTER OF 2020, BY INCOME AND COUNTRY

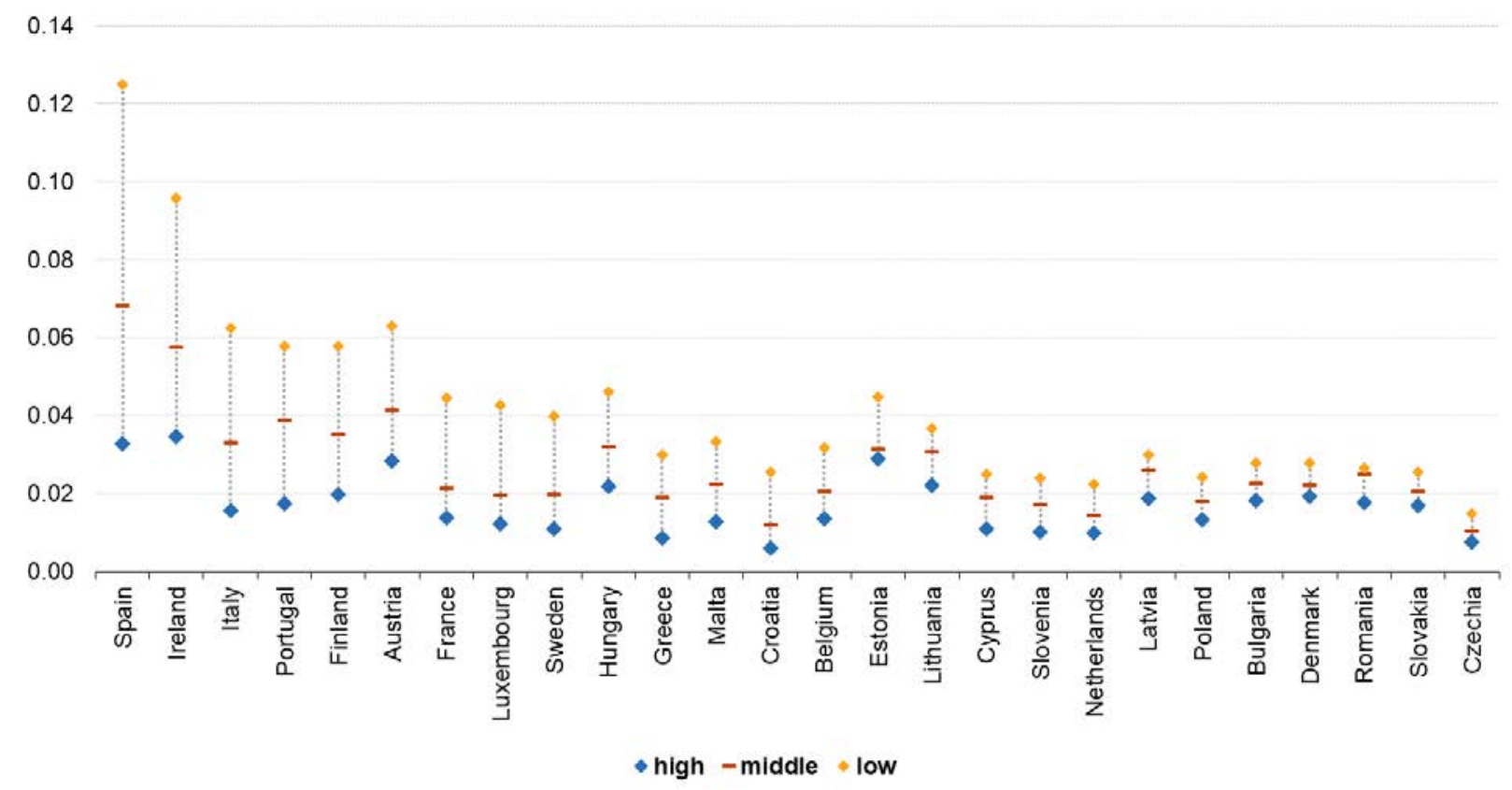

Notes: Figure from Eurostat, COVID-19 labor effects across the income distribution (December 2020).

This figure shows the probability of losing a job between the first and second quarters of 2020, by country and by income. Eurostat estimates the probability of losing a job on a 0-1 scale, using a logit model with controls for age, gender, skill level required by the occupation, sector of activity, and type of work contract (permanent, temporary or self-employment), with the European Labor Force Survey data. "Low-income" group refers to the lowest onethird decile of income distribution, "high-income" to the highest one-third, and "medium-income" to the remaining intermediate deciles. 
TABle 3: Unemployment aCROSS THE EARNings Distribution

\begin{tabular}{|c|c|}
\hline $\begin{array}{c}\text { Citation } \\
\text { Country studied }\end{array}$ & Stronger employment shock for low earners. \\
\hline $\begin{array}{l}\text { Adams-Prassl et al. (2020b) } \\
\text { UK }\end{array}$ & $\begin{array}{l}\text { From February to March } 2020 \text { employment decreased by } 12 \% \text { for } \\
\text { low-earners, } 5 \% \text { for high-earners, because of COVID- } 19 .\end{array}$ \\
\hline $\begin{array}{l}\text { Chetty et al. (2020) } \\
\text { US }\end{array}$ & $\begin{array}{l}\text { From January to mid-April 2020, employment decreased by } 37 \% \\
\text { for low-earners and by } 14 \% \text { for high-earners. }\end{array}$ \\
\hline $\begin{array}{l}\text { Li et al. (2020) } \\
\text { Australia }\end{array}$ & $\begin{array}{l}\text { In April } 2020 \text {, the propensity of dropping out of employment } \\
\text { was } 14.17 \% \text { for low-earners and } 2.58 \% \text { for high-earners. }\end{array}$ \\
\hline
\end{tabular}

Notes: In Adams-Prassl et al. (2020b) high-earners refers to households with gross labor income above $£ 40,000$ and low earners to those with less than $£ 20,000$ in 2019 . The data are from a representative survey in which respondents reported the cause of their unemployment. In Chetty et al. (2020) high and low-earners refer to top and bottom quartile of wage distribution. The authors construct a detailed new database to estimate the changes in employment. In Li et al. (2020), high- and low-earners refer to top and bottom quintile of market income (wage and business revenue) distribution. This paper uses the Monthly Longitudinal Labour Force Survey to estimate the change in employment.

\subsection{Consumption and savings}

Thanks to high-frequency, transactional data provided by banking institutions, researchers have been able to draw a picture of individuals' spending and savings patterns during the pandemic. At the aggregate level, the COVID-19 outbreak seems to have induced an increase in savings and a drop in consumption. There is consensus in the literature that mainly high-income households have contributed to these additional savings. There is less agreement on the extent to which low-income households have reduced their consumption.

The aggregate drop in consumption has been stark since the first mobility restriction measures. In Denmark, after seven weeks of lockdown (March 11-May 3, 2020), aggregate spending was $27 \%$ below what it was expected to be absent COVID-19 (Andersen et al. (2020)). In the UK, Hacioğlu-Hoke et al. (2021) find that median expenditures were almost 40\% lower in April 2020 compared to April 2019. During the first lockdown period in France, Bounie et al. (2020) report a fall in spending based on credit and debit card transactions of about 50\% during the French lockdown between mid-March and mid-May 2020.

In several countries, this trend has been highly heterogeneous across the income distribution. Low-income households undertook smaller percentage cuts to their spending, and more rapidly returned to pre-COVID19 spending levels. Higher-income earners have reduced their spending by a higher percentage, and this effect, if not permanent, seems to be longer-lasting. Table A.1 provides evidence of these patterns in several countries. ${ }^{1}$ In the US, Chetty et al. (2020) find that spending decreased by $30 \%$ between February and March 2020 for the top income quartile and by $20 \%$ for the bottom quartile. In July 2020, spending of lowincome households had returned to its 2019 level, while spending of high-income households was $13 \%$ below their baseline level. A disproportionate part of the aggregate fall in spending is thus mechanically driven by higher-income households' spending cuts. In the UK, Hacioğlu-Hoke et al. (2021) suggest that households earning more than $£ 40,000$ before the pandemic contributed to $45.3 \%$ of the decline in consumption in the second quarter of 2020 , relative to the same period in 2019 , against $9.8 \%$ for households with an annual income less than $£ 20,000$.

The mirror image of this phenomenon is the unequal distribution of the excess savings, i.e., savings that seem to be due to COVID-19. In France, Bounie et al. (2020) estimate that the pandemic has generated an excess of financial wealth by $€ 45$ billion as compared to the counterfactual (no pandemic) levels. $55 \%$ of this amount went to households in the top decile by level of total expenditure in 2019 , and $70 \%$ went to households in the top quintile.

\footnotetext{
${ }^{1}$ See Appendix A.4 for a summary of research on spending using high-frequency data.
} 
Non-essential spending represents a higher share of the spending of high-income households with respect to low-income ones (e.g., it amounts to $67 \%$ of the spending of the top income quartile and $59 \%$ for the bottom one in the US). Unsurprisingly, it was mainly non-essential spending that dropped during the pandemic, contributing $84 \%$ of the aggregate drop in the US in April 2020 relative to April 2019 (Cox et al. (2020)). Low-income households are much more constrained in their ability to cut spending and a rebound in their spending is more likely to reflect the necessity to satisfy subsistence needs rather than an improvement in their condition.

Importantly, government support might have played a key role in helping low-income groups recover their previous consumption levels and, hence, in supporting aggregate demand. As reviewed by Falcettoni and Nygaard (2021), stimulus checks in the US had a larger impact on low-income household spending. By contrast, in Spain in June 2020, low-income households' spending had not recovered faster than that for other groups. García-Montalvo and Reynal-Querol (2020) argue that insufficient government assistance to the poorest households is the main reason for this lack of recovery.

\subsection{Digital divides}

Digital literacy and infrastructure are unevenly distributed across the income distribution, leading to highly unequal opportunities and experiences during the pandemic.

Because of the increased network bandwidth usage at the global level, the least well-equipped households have suffered higher reductions in internet speeds. In addition, households with insufficient technological equipment for each member have suffered higher constraints in their potential to perform online activities at home. These two effects have strongly segmented the ability to cope with the pandemic across the income distribution. For instance, Chiou and Tucker (2020) study the ability to self-isolate in response to state requirements in the US in March 2020 and found that households living in high-income areas, benefiting from faster internet speeds, were more able to respect social distancing. The digital divide has also hampered low-income households in other ways, such as via reduced possibilities for online learning (Ong et al., 2020), as well as fewer opportunities to maintain a social life online, and adverse consequences for mental health (Beaunoyer et al., 2020). The digital divide has further played out at the regional level, with rural regions in the US being more negatively affected in these categories (Lai and Widmar, 2021).

In short, the pandemic has widened the digital divide. Financially-constrained households were most in need of investment in adequate and up-to-date equipment and network services. Yet, their experience of adverse income shocks further reduced their ability to pay for such technological investments. This in turn has reduced the possibility to leverage digital and online opportunities to make up for lost in-person ones. Overall, there has been a negative feedback effect between the pandemic and the digital divide, to the detriment of more vulnerable households (Beaunoyer et al., 2020).

\section{Inequalities across sectors and regions}

\subsection{Sectoral inequalities}

The pandemic has affected distinct sectors differently. Inequalities between sectors and across firms can be traced back to the ability to i) stay open during lockdowns, ii) substitute online for in-person activity, and iii) provide critical services during the pandemic.

Regarding the first aspect, firms fared differently based on whether they were essential or non-essential businesses and the extent to which their activity requires physical proximity to work sites, customers, or colleagues. In the US, small businesses in the leisure and hospitality sectors experienced sharper declines in revenue (57\% in March 2020) than those in the retail and transportation (of goods and people) sector (26\%) (see Chetty et al. (2020) and Figure B.2). During the lockdown in Denmark, consumer spending increased by $10 \%$ in sectors that were able to stay open and decreased by $70 \%$ in those that were not, relative to where it would have been absent COVID-19 (Andersen et al. (2020)).

Some sectors and firms have been able to maintain a sizeable share of their activity by substituting in-person sales with online ones. In France, Bounie et al. (2020) show that sectors such as personal care, 
clothing and fashion, and jewellery have substantially increased their share of online sales during the lockdown (mid-March to mid-May 2020). Across 13 countries (Albania, Chad, Cyprus, Georgia, Greece, Guinea, Italy, Moldova, Niger, Russia, Togo, Zambia, and Zimbabwe), financially-constrained firms were $22 \%$ more likely to shut down their operations and also more likely to lay off workers between May and July 2020 (Chundakkadan et al. (2020)).

Sectors that have been at the forefront of the fight against the pandemic, e.g., healthcare and pharmaceuticals, have seen improved financial performance. Bellucci et al. (2020) show that venture capital investment has been strongly reallocated during the pandemic, with health-related sectors experiencing increases in investments of $39 \%$ in the first half of 2020 .

Sectors that have been critical to coping with the lifestyle impacts of the pandemic, e.g., IT, have also benefited from higher inflows of capital and better financial performance. Sherif (2020) shows that this sector significantly outperformed the market in the UK in the first half of 2020, while sectors centered around consumer discretionary services, such as transportation (of people), tourism, and leisure, significantly underperformed. Appendix B.1 provides more detailed findings on sectoral inequalities.

\subsection{Regional inequalities in health impacts and the consequences of remote work}

Poorer regions have experienced higher COVID-19-related mortality during the pandemic, in line with the fact that social distancing was less feasible and harder to implement there. In the US, Weill et al. (2020) have shown that mobility has decreased significantly more in wealthier counties in response to state-level measures from January to April 2020. The lower potential for implementing social distancing can be explained in part by a sectoral and occupational composition effect. As shown by Brandily et al. (2020) for France, there is a higher concentration of occupations that involve physical proximity and are "essential occupations" in poorer areas. This effect is magnified by the prevalence of poor housing conditions, air pollution, deficient health infrastructure, and higher shares of elderly people. Overall, mortality from COVID-19 has been higher in poorer European regions (Kapitsinis, 2020), as well as in poorer US regions (Siddique et al., 2020).

As already alluded to in Section 2.2, the potential to work remotely is highly heterogeneous within countries. In all OECD countries, cities and urban areas benefit from higher opportunities for such work (see Ozguzel et al. (2020) and Figures 4 and B.3). But the pandemic may have led to a more long-lasting shift in remote work, which could reshape cities and suburban areas. As higher-paid employees, who are able to work remotely, move to less densely populated areas and suburbs with more affordable housing, they may be rebalancing the differences in opportunities and prices between areas. If metropolitan areas and cities then become more affordable, employees who cannot work remotely may then also be given a chance to move to these areas (Delventhal et al., 2021). These patterns may have countervailing and complex long-term consequences for productivity and inequality across regions. 
Figure 4: Share of Jobs that CAN Potentially Be PERFormed Remotely, IN CITIES, TOWNS AND RURAL AREAS IN EUROPE, 2018

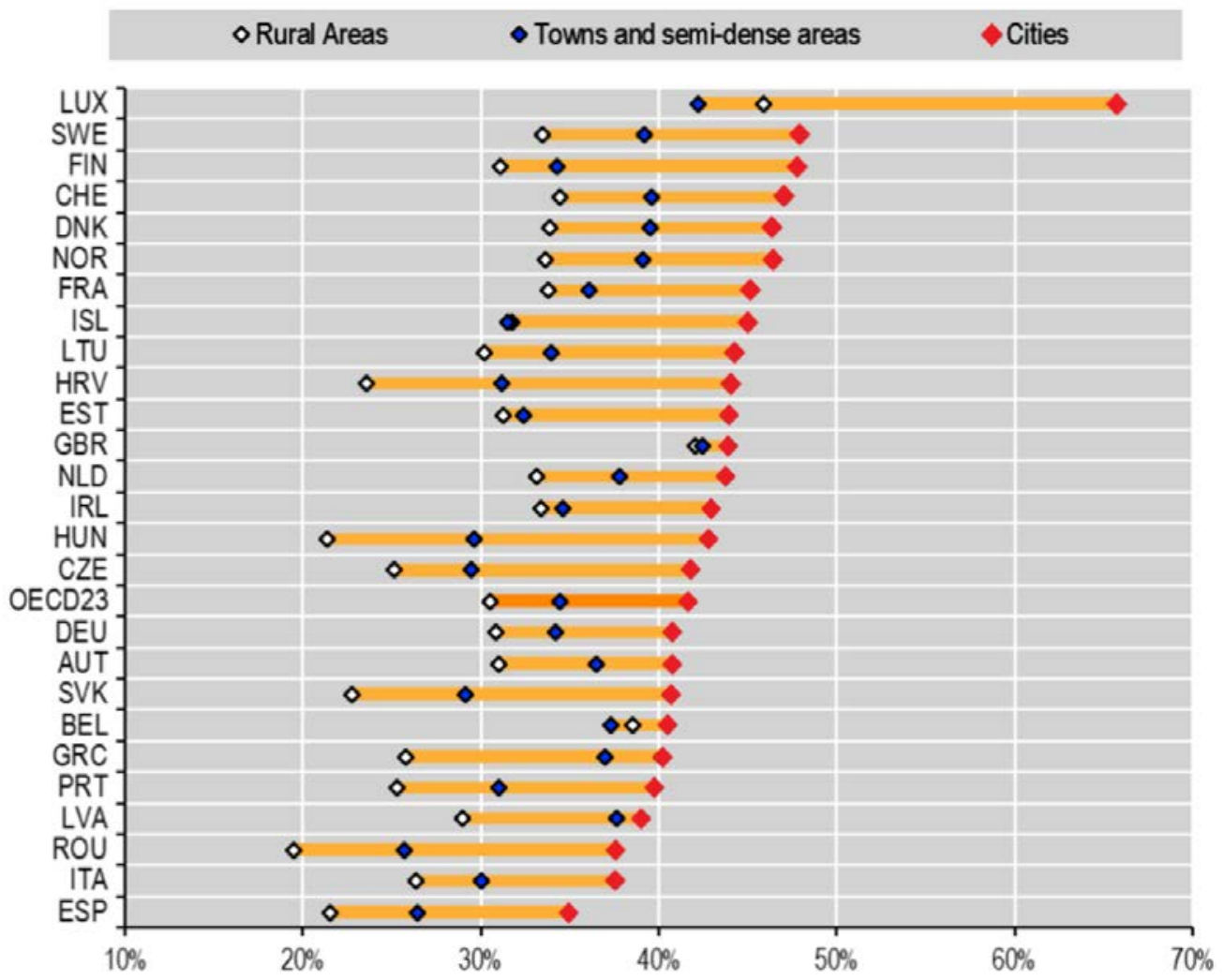

Notes: Figure from Ozguzel et al. (2020).

This figure shows the number of jobs in each country or region that can be carried out remotely as the percentage of total jobs. Countries are ranked in descending order by the share of jobs in total employment that can be done remotely at the national level. Regions correspond to NUTS-1 or NUTS-2 regions depending on data availability. The authors classify occupations based on their potential for remote work using the analysis in Dingel and Neiman (2020) and apply it to data from the European Labour Force Survey.

\section{Inequalities across gender}

This section summarizes an abundant literature on the unequal impacts of the pandemic across gender. Note that we can only focus on men and women as defined in each of the papers reviewed below. This is restrictive, but there is no systematic data for other gender groups. We also do not know whether these categories reported correspond to the people's identity.

Women experienced higher unemployment and larger reductions in work hours. School closures and additional child care responsibilities - while challenging for all parents - have especially increased unpaid domestic work for women. This section will cover remote work hours and unemployment, child care and housework.

\subsection{Remote work, work hours, and unemployment}

Compared to men, women have had a higher likelihood of being laid off, furloughed, or seeing their work hours reduced. The term "she-cession" has been employed to emphasize the unequal impacts of the pandemic- 
induced recession on men and women (Alon et al., 2020). This is in stark contrast to previous downturns, where women were less likely to lose their job.

The major causes of this disparity appear to be, first, that women tend to be more represented in some of the occupations that were hardest hit by lockdowns (e.g., hospitality, in-person services). Second, a larger share of women had part-time or alternative work contracts pre-COVID-19, while firms are more likely to shelter workers in permanent work contracts more. Thus, women were more represented among the first ones to absorb the negative shock of the recession (Adams-Prassl et al. (2020b)). Third, women quit their jobs or significantly reduced their working hours due to the increased need for childcare caused by school closures.

Working mothers were hit hardest. Alon et al. (2020) argue that the main reason for this is the massive closures of schools and daycare centers. Using the US Current Population Survey to examine changes in mothers' and fathers' work hours from February through April 2020, Collins et al. (2020) find that mothers with young children reduced their working hours four to five times more than fathers. Andrew et al. (2020) examine how parents in England living in two-parent opposite-gender families are spending their time under lockdown. They find that mothers' paid work has taken a larger hit than the work of fathers on both the extensive and intensive margins. Hipp and Bünning (2020) report similar results for Germany, where mothers were more likely to work fewer hours than fathers, and this discrepancy grew over time (from March to August 2020). Using two new online surveys from May and November 2020 in Spain, Martinez-Bravo and Sanz (2021) find that as a result of the COVID-19 shock, women saw a substantially larger decline in income than men. The largest drop in the incomes of women relative to men is for households in the middle of the income distribution (second and third quintiles). This effect seems to be driven by women in middle-income households with children.

Appendix C summarizes findings on disparities in remote work by gender.

\subsection{Childcare and housework}

The pandemic has also deepened the gender gap in unpaid work at home. School and nursery closures increased the demand for childcare, especially because grandparents, family members, or friends could not help out easily because of social distancing measures. Research shows that even though fathers increased their time spent on childcare compared to pre-COVID-19 times, mothers were the ones who absorbed most of the additional childcare work and overall housework. The results are summarized in Table 4 and in more detail in Appendix C.

Alon et al. (2020) point out that single mothers were the most vulnerable group during the pandemic. There are two reasons for this. First, single parents that were laid off during the pandemic heavily depended on external financial help. Second, school closures were particularly challenging for single parents, not the least because this study shows that they had less opportunities to work remotely. Seventeen percent of all households in the United States are single-parent households, and single mothers account for just under $70 \%$ of all single-parent households. Twenty-one percent of all children in the US live only with their mother, compared to $4 \%$ living only with their father.

The pandemic seems to also have had disproportionately negative effects on women's mental health. Appendix C.3 summarizes the research on this issue. 
TABLE 4: COVID-19 INDUCED CHANGES IN PAID AND UNPAID WORK FOR WOMEN

\begin{tabular}{|c|c|c|}
\hline Citation & Countries & Figure \\
\hline \multicolumn{3}{|c|}{ Panel A: Increase in women's transition to working from home during COVID-19 pandemic } \\
\hline $\begin{array}{l}\text { Reichelt et al. }(2020) \\
\text { Mongey and Weinberg (2020) } \\
\text { Farre et al. }(2020) \\
\text { Bonacini et al. }(2021) \\
\text { Del Boca et al. }(2020) \\
\text { Hatayama et al. }(2020) \\
\end{array}$ & $\begin{array}{l}\text { US, DE, SG } \\
\text { US } \\
\text { ES } \\
\text { IT } \\
\text { IT } \\
53 \text { countries }\end{array}$ & $\begin{array}{l}\text { Women are } 7 \text { p.p. more likely to work remotely than men. } \\
\text { Women are } 10 \text { p.p. more likely to be in high work-from-home occupations than men. } \\
\text { Women are } 6.5 \text { p.p. more likely to work remotely than men. } \\
\text { Women are } 5 \text { p.p. more likely to work remotely than men. } \\
\text { Women are } 10 \text { p.p. more likely to work remotely than men. } \\
\text { Women are more likely to work remotely than men. }\end{array}$ \\
\hline \multicolumn{3}{|c|}{ Panel B: Decline in working hours of women during COVID-19 pandemic } \\
\hline $\begin{array}{l}\text { Reichelt et al. (2020) } \\
\text { Collins et al. (2020) } \\
\text { Andrew et al. (2020) } \\
\text { Oreffice and Quintana-Domeque (2020) } \\
\text { Hipp and Bünning (2020) }\end{array}$ & $\begin{array}{l}\text { US, DE, SG } \\
\text { US } \\
\text { UK } \\
\text { UK } \\
\text { UK }\end{array}$ & $\begin{array}{c}\text { Women are } 5 \text { p.p. more likely to have reduced weekly hours than men (by at least } 10 \text { hours). } \\
\text { Mothers of young children reduced their working hours } 4 \text { to } 5 \text { times more than fathers. } \\
\text { Mothers reduced working hours by } 22 \% \text { compared to a } 16 \% \text { drop for fathers. } \\
\text { Women reduced working hours by } 50 \% \text {. } \\
\text { Women have a } 4 \text { p.p. higher likelihood to reduce working hours than men. }\end{array}$ \\
\hline \multicolumn{3}{|c|}{ Panel C: Increase in women's unemployment during COVID-19 pandemic } \\
\hline $\begin{array}{l}\text { Reichelt et al. }(2020) \\
\text { Adams-Prassl et al. (2020b) } \\
\text { Sevilla and Smith (2020) } \\
\text { Andrew et al. (2020) } \\
\text { Oreffice and Quintana-Domeque (2020) } \\
\text { Farre et al. (2020) }\end{array}$ & $\begin{array}{l}\text { US, DE, SG } \\
\text { US, UK, DE } \\
\text { UK } \\
\text { UK } \\
\text { UK } \\
\text { ES }\end{array}$ & $\begin{array}{l}\text { Women have a } 3 \text { p.p. higher likelihood of having transitioned to unemployment. } \\
\text { Women have a } 7(5)(0) \text { p.p. higher likelihood of losing jobs compared to men in the US (UK) (DE). } \\
\text { Women have a } 7 \text { p.p. higher likelihood of losing their job compared to men. } \\
\text { Mothers have a } 9 \text { p.p. higher likelihood of losing their job compared to fathers. } \\
\text { Women have a } 4.2 \text { p.p. higher likelihood to have lost jobs than men. } \\
\text { Women have a } 2.5 \text { p.p. higher likelihood to have lost jobs than men. }\end{array}$ \\
\hline \multicolumn{3}{|c|}{ Panel D: Increase in women's childcare responsibilities during COVID-19 pandemic } \\
\hline $\begin{array}{l}\text { Adams-Prassl et al. (2020b) } \\
\text { Alon et al. (2020) } \\
\text { Sevilla and Smith (2020) } \\
\text { Andrew et al. (2020) } \\
\text { Hupkau and Petrongolo (2020) } \\
\text { Farre et al. (2020) } \\
\quad \text { Fodor et al. (2020) }\end{array}$ & $\begin{array}{l}\text { US, UK, DE } \\
\text { US } \\
\text { UK } \\
\text { UK } \\
\text { UK } \\
\text { ES } \\
\text { HU }\end{array}$ & $\begin{array}{c}\text { Women spend on average } 1.5 \text { hours more on childcare than men. } \\
\text { Women provide } 60 \% \text { of childcare hours. } \\
\text { Women do } 30.3 \text { more hours of childcare per week compared to } 19.4 \text { done by men. } \\
\text { Mothers engage in childcare over } 25 \% \text { more hour-long slots than fathers. } \\
\text { Women do } 9.5 \text { more hours of increased childcare compared to } 6.9 \text { hours done by men. } \\
\text { Mothers spend } 34.6 \text { hours on childcare per week compared to } 24.9 \text { hours spent by fathers. } \\
\text { Women spend an additional } 5 \text { hours a week on childcare compared to men. }\end{array}$ \\
\hline
\end{tabular}

Notes: The table summarizes results from a variety of studies on the effects of COVID-19 on paid and unpaid work for women and mothers. "P.p." stands for percentage points. 


\section{Inequalities in education}

Nursery, kindergarten, school, and university closures were some of the earliest and most widespread responses to the pandemic. In April 2020, UNESCO reported that 192 countries had closed all their schools and universities, affecting more than $90 \%$ of the world's students. The impacts on children in the short run have been striking, and research has tried to estimate the longer-term consequences.

\subsection{Time spent learning and learning delays}

In the short term, children, especially those from disadvantaged socio-economic backgrounds, have spent significantly less time on school work during school closures, which has had consequences for their education.

For younger children, the lack of face-to-face time can translate into substantially less learning. Bao et al. (2020) predict a 31\% lower reading gain from January to September 2020, relative to a business-as-usual scenario for kindergarten children whose schools were closed. They also find that parental input can help, but not make up for this: children who have books read to them daily had lower, but nonetheless substantial learning loss.

Huber and Helm (2020) conducted a survey and tracked students' efforts on school-related work in Switzerland, Austria, and Germany for two weeks, in the very early stages of the lockdowns (March 24 April 5, 2020). During that period, very few online classes had been put into place, meaning that students had to study on their own. The authors find that a substantial proportion of students reported learning at home during school lockdown for at most two hours per day (see Figure D.2). Only a third of students reported a relatively high level of learning commitment (more than five hours per day).

Grewenig et al. (2021) collected detailed time-use information on students before and during school closures in Germany in June 2020, when online classes had mostly been put in place. They find that students on average reduced their daily learning time of 7.4 hours by about half, and that the reduction was significantly larger for students with lower test scores (4.1 hours) than for those with higher test scores (3.7 hours) (see Figure D.1). Unfortunately, parental or teachers' inputs could not substitute for school closures, and students with lower test scores appear to have substituted learning time with leisure activities such as TV or video games.

Andrew et al. (2020) confirm these results and find that there is considerable heterogeneity by family income in children's learning experiences. Not only does the time children spend on learning differ between lower- and higher-income families, but so do the resources available at home and provided by schools. BacherHicks et al. (2021) use high-frequency internet search data to study in real time how US households sought out online learning resources once schools closed. Urban areas with higher income and better internet access exhibited substantially larger increases in searches for online learning resources. The analysis of Jæger and Blaabæk (2020) for Denmark also suggests that higher income groups have enjoyed greater learning opportunities during the pandemic. Agostinelli et al. (2020) employ a theoretical framework to predict that school closures could have a large and persistent effect on educational outcomes that is highly unequal.

In the Netherlands, Engzell et al. (2020) find that primary school closures essentially halted learning, and that some students even regressed in their educational attainment. Furthermore, the learning delays were much more pronounced among students with less- educated parents (see Figure D.4). These results are particularly concerning given that the Netherlands could be considered a "best case" scenario, suggesting that countries with higher educational inequality at baseline and fewer resources could face even worse outcomes. These findings are echoed by those in Maldonado and De Witte (2021) for Flemish primary schools in Belgium.

\subsection{Unequal technical and resource constraints}

After schools physically closed due to the pandemic, many tried to create an online learning environment. This was not an easy transition for neither schools nor for students, in part because not all schools and students had access to adequate technical equipment for online schooling. The lack of technical equipment, robust curricula adapted to online environments, and missing digital infrastructure further amplified educational inequalities. Huber and Helm (2020) document the starkly different technical capacities for digital 
instruction across schools in different countries and conclude that Switzerland and Austria have significantly more resources and technical capacities for digital teaching than Germany (see Figure D.3). Another side of the problem is documented in England, where Andrew et al. (2020) find that one in ten students in primary school and one in seven students in secondary school relied only on a cellphone or had no digital device to access school materials online.

\subsection{Longer-term impacts.}

The longer-term impacts stem from the immediate loss of schooling time, but also from the dynamic effects of human capital accumulation, whereby earlier acquisitions improve the productivity of future human capital investments. Disruptions earlier on in life can have longer lasting and more severe effects. This implies that younger children may be more heavily impacted than older ones. Psacharopoulos et al. (2020) estimate that a four-month school interruption results in an earnings loss of $\$ 11,117$ over the course of a lifetime of an individual. Using a theoretical framework and simulations matched to US data, Fuchs-Schündeln et al. (2020) find that the share of the population without a high school degree will increase by $3.8 \%$ and the share with a college degree will decrease by $2.7 \%$. Earning losses amount to about $-1 \%$ over the lifetimes.

\section{Conclusion}

The COVID-19 pandemic has had far-reaching consequences for individuals and economies. The effect of the pandemic on inequalities are concerning. Vulnerable groups such as low-income workers and students from disadvantaged backgrounds were often affected not only more severely, but have also recovered less quickly. While remote work became standard for some during the pandemic, the ability to work remotely and thus remain physically safe from infection - varied across sectors and regions. For women, the pandemic often entailed disproportionately more unpaid domestic work and the loss of paid working hours. The loss of in-person education for students ranks among the devastating impacts of the pandemic that are likely to have long term consequences. Addressing these inequalities will be a key aspect of ensuring a fair and equitable recovery.

\section{References}

Adams-Prassl, A., T. Boneva, M. Golin, and C. Rauh (2020a). The Impact of the Coronavirus Lockdown on Mental Health: Evidence from the US. Cambridge Working Papers in Economics 2037. Journal of Public Economics 189, 104245.

Adams-Prassl, A., T. Boneva, M. Golin, and C. Rauh (2020b). Inequality in the Impact of the Coronavirus Shock: Evidence from Real Time Surveys. IZA Discussion Paper 13183.

Adams-Prassl, A., T. Boneva, M. Golin, and C. Rauh (2020c). Work That Can Be Done from Home: Evidence on Variation within and across Occupations and Industries. IZA Discussion Paper 13374.

Agostinelli, F., M. Doepke, G. Sorrenti, and F. Zilibotti (2020). When the Great Equalizer Shuts Down: Schools, Peers, and Parents in Pandemic Times. NBER Working Paper 28264.

Almeida, V., S. Barrios, M. Christl, S. De Poli, A. Tumino, and W. van der Wielen (2020). Households' income and the cushioning effect of fiscal policy measures during the Great Lockdown. JRC Working Papers on Taxation \& Structural Reforms 2020-06, Joint Research Centre (Seville site).

Alon, T., M. Doepke, J. Olmstead-Rumsey, and M. Tertilt (2020). The Impact of COVID-19 on Gender Equality. NBER Working Paper 26947. CRC TR 224 Discussion Paper Series.

Andersen, A. L., E. T. Hansen, N. Johannesen, and A. Sheridan (2020). Consumer Responses to the COVID-19 Crisis: Evidence from Bank Account Transaction Data. SSRN Scholarly Paper ID 3612880, Social Science Research Network, Rochester, NY. 
Andrew, A., S. Cattan, M. Costa Dias, C. Farquharson, L. Kraftman, S. Krutikova, A. Phimister, and A. Sevilla (2020, january). The Gendered Division of Paid and Domestic Work under Lockdown. IZA Discussion Paper 13500.

Andrew, A., S. Cattan, M. C. Dias, C. Farquharson, L. Kraftman, S. Krutikova, A. Phimister, and A. Sevilla (2020, december). Inequalities in Children's Experiences of Home Learning during the COVID-19 Lockdown in England*.

Angelopoulos, K., S. Lazarakis, R. Mancy, and M. Schroeder (2021, December). Pandemic-Induced Wealth and Health Inequality and Risk Exposure. CESifo Working Paper 9474.

Aspachs, O., R. Durante, A. Graziano, J. Mestres, J. G. Montalvo, and M. Reynal-Querol (2020). Real-time inequality and the welfare state in motion: Evidence from COVID-19 in Spain. Technical Report 1734, Department of Economics and Business, Universitat Pompeu Fabra.

Bacher-Hicks, A., J. Goodman, and C. Mulhern (2021, January). Inequality in household adaptation to schooling shocks: Covid-induced online learning engagement in real time. Journal of Public Economics 193, 104345 .

Banks, J. and X. Xu (2020). The Mental Health Effects of the First Two Months of Lockdown during the COVID-19 Pandemic in the UK. Fiscal Studies 41(3), 685-708.

Bao, X., H. Qu, R. Zhang, and T. P. Hogan (2020, January). Modeling Reading Ability Gain in Kindergarten Children during COVID-19 School Closures. International Journal of Environmental Research and Public Health 17(17), 6371.

Barbieri, T., G. Basso, and S. Scicchitano (2020). Italian workers at risk during the COVID-19 epidemic. Questioni di Economia e Finanza (Occasional Papers).

Beaunoyer, E., S. Dupéré, and M. J. Guitton (2020, October). COVID-19 and digital inequalities: Reciprocal impacts and mitigation strategies. Computers in Human Behavior 111, 106424.

Bellucci, A., A. Borisov, G. Gucciardi, and A. Zazzaro (2020). The Reallocation Effects of COVID-19: Evidence from Venture Capital Investments around the World. Mo.Fi.R. Working Paper 167, Money and Finance Research group (Mo.Fi.R.) - Univ. Politecnica Marche - Dept. Economic and Social Sciences.

Bick, A., A. Blandin, Virginia Commonwealth University, K. Mertens, and Federal Reserve Bank of Dallas (2020, July). Work from Home After the COVID-19 Outbreak. Federal Reserve Bank of Dallas, Working Papers 2020(2017).

Blanchard, O. and L. Summers (1986). Hysteresis and the European Unemployment Problem. NBER macroeconomics annual 1, 15-78.

Boll, C., D. Müller, and S. Schüller (2021). Neither Backlash Nor Convergence: Dynamics of Intracouple Childcare Division after the First COVID-19 Lockdown and Subsequent Reopening in Germany. CESifo Working Paper No. 9091.

Bonacini, L., G. Gallo, and S. Scicchitano (2021, January). Working from home and income inequality: Risks of a 'new normal' with COVID-19. Journal of Population Economics 34(1), 303-360.

Bounie, D., Y. Camara, E. Fize, J. Galbraith, C. Landais, C. Lavest, T. Pazem, and B. Savatier (2020). Consumption Dynamics in the COVID Crisis: Real Time Insights from French Transaction \& Bank Data. Technical Report 15474, Centre for Economic Policy Research.

Bounie, D., Y. Camara, and J. W. Galbraith (2020). Consumers' Mobility, Expenditure and Online-Offline Substitution Response to COVID-19: Evidence from French Transaction Data. SSRN Scholarly Paper ID 3588373, Social Science Research Network, Rochester, NY. 
Brandily, P., C. Brebion, S. Briole, and L. Khoury (2020). A Poorly Understood Disease? the Unequal Distribution of Excess Mortality Due to COVID-19 Across French Municipalities. SSRN Scholarly Paper ID 3682513, Social Science Research Network, Rochester, NY.

Brülhart, M. and R. Lalive (2020). Daily Suffering: Helpline Calls during the Covid-19 Crisis. Covid Economics (20), 143-159.

Brunori, P., M. L. Maitino, L. Ravagli, and N. Sciclone (2020). Distant and Unequal. Lockdown and Inequalities in Italy. Technical Report 13, Universita' degli Studi di Firenze, Dipartimento di Scienze per l'Economia e l'Impresa.

Chetty, R., J. N. Friedman, N. Hendren, M. Stepner, and T. O. I. Team (2020). The Economic Impacts of COVID-19: Evidence from a New Public Database Built Using Private Sector Data. NBER Working Paper 27431. National Bureau of Economic Research.

Chiou, L. and C. Tucker (2020). Social Distancing, Internet Access and Inequality. NBER Working Paper 26982. National Bureau of Economic Research.

Chundakkadan, R., R. Raj, and S. Sasidharan (2020). Small Firms amidst COVID-19: Financial Constraints and Role of Government Support. SSRN Scholarly Paper ID 3691564, Social Science Research Network, Rochester, NY.

Clark, A., C. D'Ambrosio, and A. Lepinteur (2020). The Fall in Income Inequality during COVID-19 in Five European Countries. Working Paper 565, ECINEQ, Society for the Study of Economic Inequality.

Collins, C., L. C. Landivar, L. Ruppanner, and W. J. Scarborough (2020, July). COVID-19 and the gender gap in work hours. Gender, Work 83 Organization 28(S1), 101-112.

Cox, N., P. Ganong, P. Noel, J. Vavra, A. Wong, D. Farrell, F. Greig, and E. Deadman (2020). Initial Impacts of the Pandemic on Consumer Behavior: Evidence from Linked Income, Spending, and Savings Data. Brookings Papers on Economic Activity 2020(2), 35-82.

Crowley, F. and J. Doran (2020). COVID-19, occupational social distancing and remote working potential: An occupation, sector and regional perspective. Regional Science Policy \&3 Practice 12(6), 1211-1234.

Czymara, C. S., A. Langenkamp, and T. Cano (2020, August). Cause for concerns: Gender inequality in experiencing the COVID-19 lockdown in Germany. European Societies, 1-14.

De Fraja, G., J. Matheson, and J. Rockey (2020). Zoomshock: The Geography and Local Labour Market Consequences of Working from Home. SSRN Scholarly Paper ID 3752977, Social Science Research Network, Rochester, NY.

Del Boca, D., N. Oggero, P. Profeta, and M. C. Rossi (2020). Women's Work, Housework and Childcare, before and during COVID-19. IZA Discussion Paper 13409.

del Rio-Chanona, R. M., P. Mealy, A. Pichler, F. Lafond, and J. D. Farmer (2020, September). Supply and demand shocks in the COVID-19 pandemic: An industry and occupation perspective. Oxford Review of Economic Policy 36(Supplement_1), S94-S137.

Delventhal, M. J., E. Kwon, and A. Parkhomenko (2021, March). How Do Cities Change When We Work from Home? Journal of Urban Economics, 103331.

Deryugina, T., O. Shurchkov, and J. Stearns (2021). COVID-19 Disruptions Disproportionately Affect Female Academics. AEA Papers and Proceedings 111, 164-168.

Dijst, M., C. D’Ambrosio, V. V. Acker, P. V. Kerm, L. Martin, S. Cosaert, I. Gewinner, L. Görges, M. Suhrcke, T. Seuring, and C. Vögele (2021). SEI Socio-Economic Impacts of COVID-19: Collecting the data. Fonds National de la Recherche-FNR, Luxembourg Institute of Socio-Economics Research (LISER). 
Dingel, J. I. and B. Neiman (2020, September). How many jobs can be done at home? Journal of Public Economics 189, 104235.

Doyle, O. (2020). COVID-19: Exacerbating Educational Inequalities? working Paper.

Engzell, P., A. Frey, and M. D. Verhagen (2020). Learning Inequality During the Covid-19 Pandemic. Mimeo, University of Oxford.

Etheridge, B. and L. Spantig (2020). The gender gap in mental well-being during the Covid-19 outbreak: Evidence from the UK. ISER Working Paper 2020-08.

Etheridge, B., Y. Wang, and L. Tang (2020). Worker productivity during lockdown and working from home: Evidence from self-reports. Covid Economics (52), 118-151.

Falcettoni, E. and V. M. Nygaard (2021, January). A Literature Review on the Impact of Increased Unemployment Insurance Benefits and Stimulus Checks in the United States. Covid Economics (64), 186-201.

Farre, L., Y. Fawaz, L. Gonzales, and J. Graves (2020). How the COVID-19 Lockdown Affected Gender Inequality in Paid and Unpaid Work in Spain. IZA Discussion Paper 13434.

Fodor, É., A. Gregor, J. Koltai, and E. Kováts (2020). The impact of COVID-19 on the gender division of childcare work in Hungary. European Societies, 1-16.

Fuchs-Schündeln, N., D. Krueger, A. Ludwig, and I. Popova (2020). The Long-Term Distributional and Welfare Effects of Covid-19 School Closures. NBER Working Paper 27773.

Gao, G. and L. Sai (2020). Towards a 'virtual' world: Social isolation and struggles during the COVID-19 pandemic as single women living alone. Gender, Work 83 Organization 27(5), 754-762.

García-Montalvo, J. and M. Reynal-Querol (2020). Distributional Effects of COVID-19 on Spending: A First Look at the Evidence from Spain. Working Paper 1201, Barcelona Graduate School of Economics.

Grewenig, E., P. Lergetporer, K. Werner, L. Woessmann, and L. Zierow (2021). COVID-19 and Educational Inequality: How School Closures Affect Low- and High-Achieving Students. European Economic Review 140.

Hacıŏlu-Hoke, S., D. R. Känzig, and P. Surico (2021, February). The Distributional Impact of the Pandemic. European Economic Review, 103680.

Hatayama, M., M. Viollaz, and H. Winkler (2020). Jobs' Amenability to Working from Home: Evidence from Skills Surveys for 53 Countries. World Bank Policy Research Working Paper No. 9241.

Hipp, L. and M. Bünning (2020, October). Parenthood as a driver of increased gender inequality during COVID-19? exploratory evidence from Germany. European Societies, 1-16.

Huber, S. G. and C. Helm (2020). COVID-19 and schooling: Evaluation, assessment and accountability in times of crises - reacting quickly to explore key issues for policy, practice and research with the school barometer. Educational Assesment, Evaluation and Accountability 32(2), 237-270.

Hupkau, C. and B. Petrongolo (2020). Work, Care and Gender during the COVID-19 Crisis. Fiscal Studies $41(3), 623-651$.

Immel, L., F. Neumeier, and A. Peichl (2021). The Unequal Consequences of the Covid-19 Pandemic: Evidence from a Large Representative German Population Survey. CESifo Working Paper No. 9038.

Irlacher, M. and M. Koch (2021). Working from Home, Wages, and Regional Inequality in the Light of COVID-19. Jahrbücher für Nationalökonomie und Statistik 241(3).

Jæger, M. M. and E. H. Blaabæk (2020, August). Inequality in learning opportunities during Covid-19: Evidence from library takeout. Research in Social Stratification and Mobility 68, 100524. 
Kapitsinis, N. (2020). The underlying factors of the COVID-19 spatially uneven spread. Initial evidence from regions in nine EU countries. Regional Science Policy 83 Practice 12(6), 1027-1045.

Kristal, T. and M. Yaish (2020, August). Does the coronavirus pandemic level the gender inequality curve? (It doesn't). Research in Social Stratification and Mobility 68, 100520.

Lai, J. and N. O. Widmar (2021). Revisiting the Digital Divide in the COVID-19 Era. Applied Economic Perspectives and Policy 43(1), 458-464.

Li, J., Y. Vidyattama, H. A. La, R. Miranti, and D. M. Sologon (2020). The Impact of COVID-19 and Policy Responses on Australian Income Distribution and Poverty. Technical Report 2009.04037, arXiv.org.

Maldonado, J. and K. De Witte (2021). The effect of school closures on standardised student test outcomes. British Educational Research Journal.

Martinez-Bravo, M. and C. Sanz (2021). Inequality and Psychological Well-being in Times of Covid-19: Evidence from Spain. CEMFI Working Paper.

Mongey, S. and A. Weinberg (2020). Characteristics of Workers in Low Work-From-Home and High PersonalProximity Occupations. White Paper.

O'Donoghue, C., D. M. Sologon, I. Kyzyma, and J. McHale (2020). Modelling the Distributional Impact of the COVID-19 Crisis. Fiscal Studies 41(2), 321-336.

Ong, P., D. Mar, T. Larson, and J. H. Peoples (2020). COVID-19 and the Digital Divide in Virtual Learning. UCLA Center for Neighborhood Knowledge.

Oreffice, S. and C. Quintana-Domeque (2020). Gender Inequality in COVID-19 Times: Evidence from UK Prolific Participants. IZA Discussion Paper 13463.

Ozguzel, C., P. Veneri, and R. Ahrend (2020). Capacity for remote working can affect lockdown costs differently across places. OECD.

Palomino, J. C., J. G. Rodríguez, and R. Sebastian (2020, October). Wage inequality and poverty effects of lockdown and social distancing in Europe. European Economic Review 129, 103564.

Petts, R. J., D. L. Carlson, and J. R. Pepin (2021). A gendered pandemic: Childcare, homeschooling, and parents' employment during COVID-19. Gender, Work $\& 3$ Organization 28(S2), 515-534.

Phelps, E. S. (1972). Inflation Policy and Unemployment Theory: The cost-benefit approach to monetary planning. Norton.

Pieh, C., S. Budimir, and T. Probst (2020, September). The effect of age, gender, income, work, and physical activity on mental health during coronavirus disease (COVID-19) lockdown in Austria. Journal of Psychosomatic Research 136, 110186.

Piyapromdee, S. and P. Spittal (2020). The Income and Consumption Effects of COVID-19 and the Role of Public Policyen. Fiscal Studies 41(4), 805-827.

Psacharopoulos, G., V. Collis, H. Patrinos, and E. Vegas (2020). Lost Wages: The COVID-19 Cost of School Closures. IZA Discussion Paper 13641.

Reichelt, M., K. Makovi, and A. Sargsyan (2020, September). The impact of COVID-19 on gender inequality in the labor market and gender-role attitudes. European Societies 23(sup1), S228-S245.

Sevilla, A. and S. Smith (2020). Baby Steps: The Gender Division of Childcare during the COVID-19 Pandemic. Oxford Review of Economic Policy.

Sherif, M. (2020, December). The impact of Coronavirus (COVID-19) outbreak on faith-based investments: An original analysis. Journal of Behavioral and Experimental Finance 28, 100403. 
Siddique, A. B., K. E. Haynes, R. Kulkarni, and M.-H. Li (2020). Impact of Poverty on COVID-19 Infections and Fatalities: A Regional Perspective. SSRN Scholarly Paper ID 3702682, Social Science Research Network, Rochester, NY.

Sostero, M., S. Milasi, J. Hurley, E. Fernandez-Macias, and M. Bisello (2020). Teleworkability and the COVID-19 crisis: A new digital divide? JRC Working Paper Series on Labour, Education and Technology No. $2020 / 05$.

Stiglitz, J. E. (2020). The Pandemic Economic Crisis, Precautionary Behavior, and Mobility Constraints: An Application of the Dynamic Disequilibrium Model with Randomness. NBER Working Paper 27992. National Bureau of Economic Research.

Tyson, L. and S. Lund (2021). The Post-Pandemic Labor Market's Long-Term Scars. Project Syndicate.

Weill, J. A., M. Stigler, O. Deschenes, and M. R. Springborn (2020). Social distancing responses to COVID19 emergency declarations strongly differentiated by income. Proceedings of the National Academy of Sciences 117(33), 19658-19660.

Yamamura, E. and Y. Tsutsui (2020). Impact of the State of Emergency Declaration for COVID-19 on Preventive Behaviors and Mental Conditions in Japan: Difference in Difference Analysis using Panel Data. arXiv:2005.13008.

Zamarro, G. and M. J. Prados (2021). Gender differences in couples' division of childcare, work and mental health during COVID-19. Review of Economics of the Household 19(1), 11-40.

Zoch, G., A.-C. Bächmann, and B. Vicari (2021). Who cares when care closes? Care-Arrangements and parental working conditions during the COVID-19 pandemic in Germany. European Societies, 1-13. 


\section{APPENDIX}

\section{A Inequalities across the income distribution}

\section{A.1 Evolution of income inequalities}

- Almeida et al. (2020)

The authors use the micro-simulation model EUROMOD to estimate the effect of changes in GDP and employment induced by the pandemic during the spring of 2020 on household income for 27 European countries. They compute the distribution of disposable income, equivalized for household size and composition, taking into account the discretionary measures that have been implemented by the 27 European countries they study. They also compute the counterfactual distribution, under a scenario where no discretionary measures are taken in response to the pandemic. Then they estimate the Gini coefficient of these two distributions. They estimate that without policy measures, the Gini coefficient would have increased by $3.6 \%$, while it has decreased by $0.7 \%$ with the policy response.

- Aspachs et al. (2020)

The authors use high-frequency, high-quality microdata from back-records to track the evolution of income inequality, and its effect on different groups of the population in the aftermath of the COVID19 pandemic. They use aggregated and anonymized data from the second largest Spanish financial institution (CaixaBank) on payroll and benefits for more than 3 million wage earners. They provide a methodology to calculate monthly Gini indices, before and after accounting for public benefits, to analyze if the schemes to support workers who are temporarily out of the labor market are working well enough to keep inequality at a low level. Results show that in absence of public benefit schemes, inequality would have increased dramatically. The impact of the crisis on inequality is explained mostly by its effect on low-wage workers. Pre-benefits wage inequality has increased significantly among foreign-borns individuals and regions that have a heavy economic dependence on tourism. Public benefits activated soon after the beginning of the pandemic have substantially mitigated the impact of the COVID-19 crisis on inequality.

- Brunori et al. (2020)

The authors use the micro-simulation model MicroReg tax microsimulation from IRPET ${ }^{2}$ to estimate the change in equivalized disposable income distribution induced by the pandemic in Italy during the spring 2020. They consider the measures that have been implemented, in addition to a counterfactual scenario without policy support. They estimate that without policy measures, the Gini coefficient would have increased by $0.67 \%$, while it has decreased by $0.67 \%$ with the policy response.

- Palomino et al. (2020)

The authors estimate the effect of legal restrictions during lockdown periods in the spring 2020 on wage distribution for 29 European countries. After estimating the ability of workers to perform their jobs during the lockdown period, they compute wage distribution under four different scenarios: The first one with a two-month lockdown, and three others, where the lockdown period is followed by six months of partial functioning of closed activities, at $60 \%, 70 \%$ or $80 \%$ of full capacity. This leads to a range of Gini coefficients associated with each counterfactual wage distribution. In the more stringent scenario with partial functioning at $60 \%$, the Gini coefficient increases by $7.3 \%$, against $3.5 \%$ in the more optimistic scenario.

- O’Donoghue et al. (2020)

The authors use the European Union Survey on Income and Living Conditions to calibrate their own microsimulation model for Ireland and estimate the change in income distribution induced by the pandemic in Ireland during the spring 2020. They estimate both the distribution of market income and

\footnotetext{
${ }^{2}$ Istituto Regionale per la Programmazione Economica della Toscana
} 
disposable income, equivalized for housing, work-related expenses, and capital losses. They compute that the Gini coefficient of market income has increased by $20.64 \%$ as compared to before the pandemic, while the Gini of disposable income has decreased by $6.62 \%$.

- Li et al. (2020)

The authors use a semiparametric approach to estimate the impact of the pandemic on Australian income and employment distribution during the spring of 2020. They estimate both the distribution of market income and equivalized disposable income. They compute that between February and June 2020, the Gini coefficient of market income has increased by $3.33 \%$ as compared to before the pandemic, while the Gini of disposable income decreased by $7.57 \%$.

- Clark et al. (2020)

The authors use longitudinal high-frequency data from a representative survey of 7,302 respondents to directly estimate the changes in income distribution over the year 2020 for France, Germany, Italy, Spain, and Sweden. They compute the changes in the Gini coefficient of equivalized disposable income. Between January and May 2020, the Gini increased by $2.17 \%$ on average; between January and September 2020 , it decreased by $2.48 \%$.

- Angelopoulos et al. (2021)

The authors use a Bewley model to analyze the effect of the pandemic on wealth accumulation of heterogeneous households in the UK The model is calibrated using the Wealth and Asset Survey. Authors model the crisis as an increase in labor income risk, a drop in mean income, and an upper bound on consumption to capture the restrictions associated with lockdown periods. They consider both short and long recession scenarios with recovery in 2024 and 2027, respectively. In both scenarios, the consequences on wealth accumulation propagate over time and increase wealth inequalities persistently. The first driver of inequality is the labor income shock, which hits low-income households harder, leading them to decrease their savings. The second is consumption restrictions, which lead high-income households to increase their savings.

- Martinez-Bravo and Sanz (2021)

The authors use two novel online surveys collected in May and November 2020 to study the consequences of the COVID-19 pandemic on Spanish households. In this study they focus on the 2,678 individuals older than 18 that completed both questionnaires and provided full information in key variables such as monthly income, occupation and measures of well-being. The resulting sample is representative of the Spanish population in terms of gender, education, and region of residence. The results show that the poorest households experienced substantially larger shocks relative to richer households. While households in the richest quintile of the income distribution had lost $7 \%$ of their household income by May 2020, the decline was of $28 \%$ of those in the poorest quintile. In order to set results in comparison to with previous studies, they compute the Gini coefficient in three different points in time: in 2019, in May 2020, and in November 2020. The resulting estimates are 0.36, 0.39, and 0.38 respectively. 
Figure A.1: Estimated Changes in InCOME AND SPENDing Between SPRING 2019 AND 2020 IN THE US, BY INCOME QUARTILES
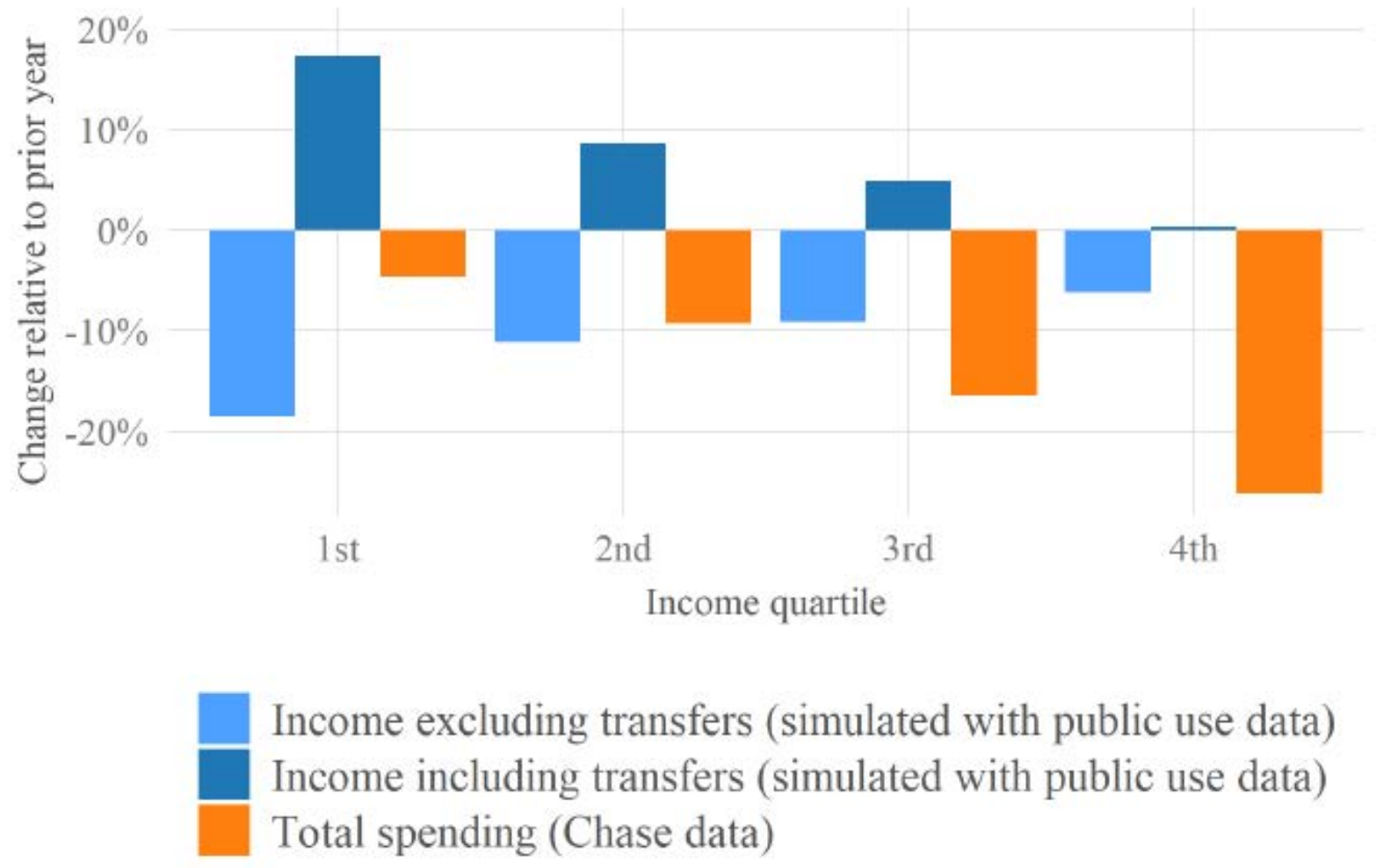

Notes: Figure from Cox et al. (2020).

This figure shows the change in income and spending by income quartile. The change in income compares March, April, and May 2020 to average quarterly income in the prior year. The change in income reflects the decline in labor income, the EIPs, and unemployment benefits. The change in spending compares April 15-May 30 to spending at the same time in the prior year and is computed using accounts data from Chase Bank. 
Figure A.2: Evolution of income inequality measures in Europe over 2020
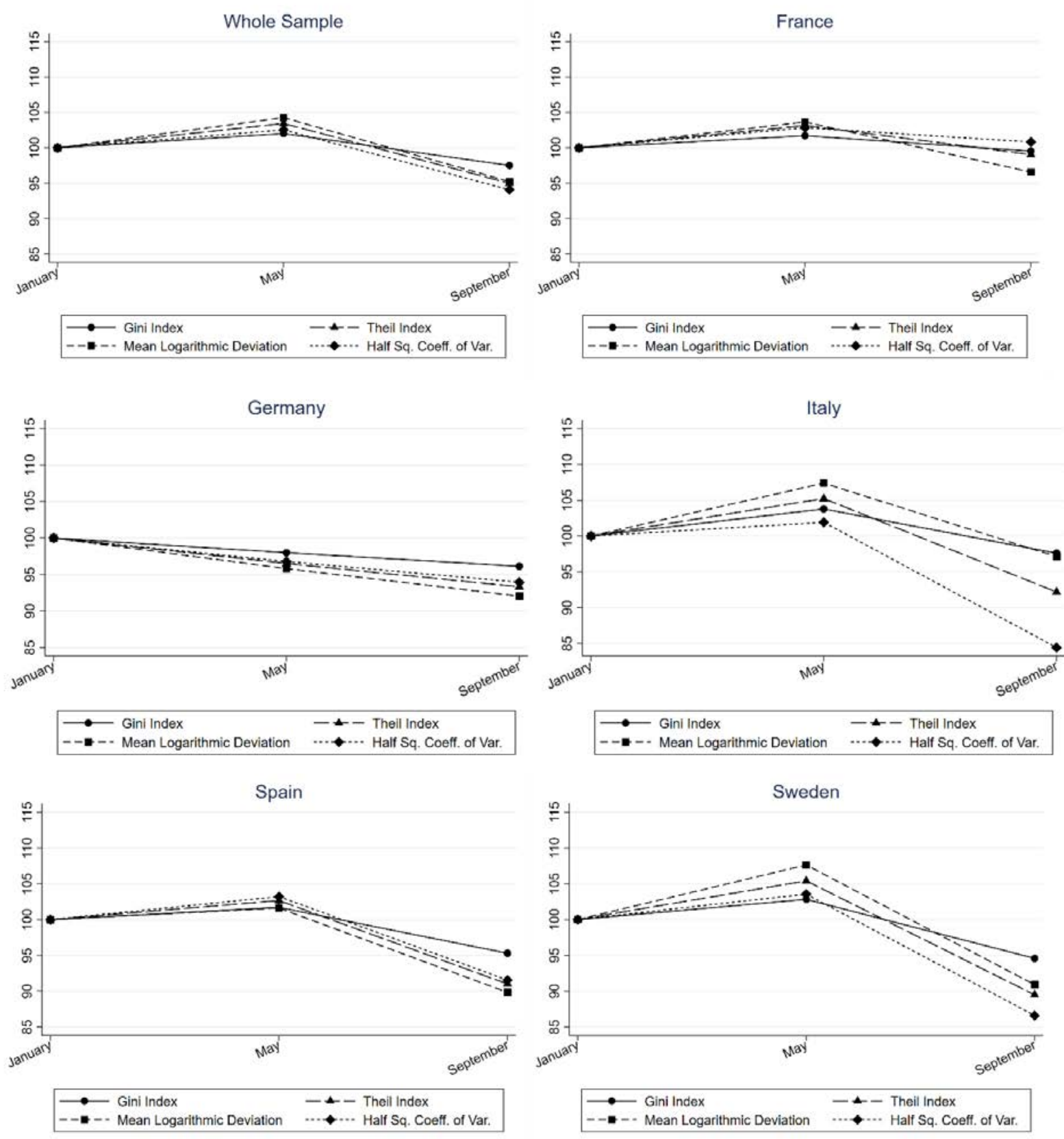

Notes: Figure from Clark et al. (2020).

These figure shows the evolution of Gini coefficient of equivalized disposable income distribution as well as three other measures of inequalities, the mean logarithmic deviation, the Theil index and the half square of the coefficient of variation. They are estimated for January, May, and September 2020, using a longitudinal representative survey data of 7,302 respondents. 
FIGURE A.3: IMPACT OF SPRING 2020 LOCKDOWNS ON INCOME INEQUALITY (GINI
INDEX) IN EU COUNTRIES, WITH AND WITHOUT POLICY ANSWERS

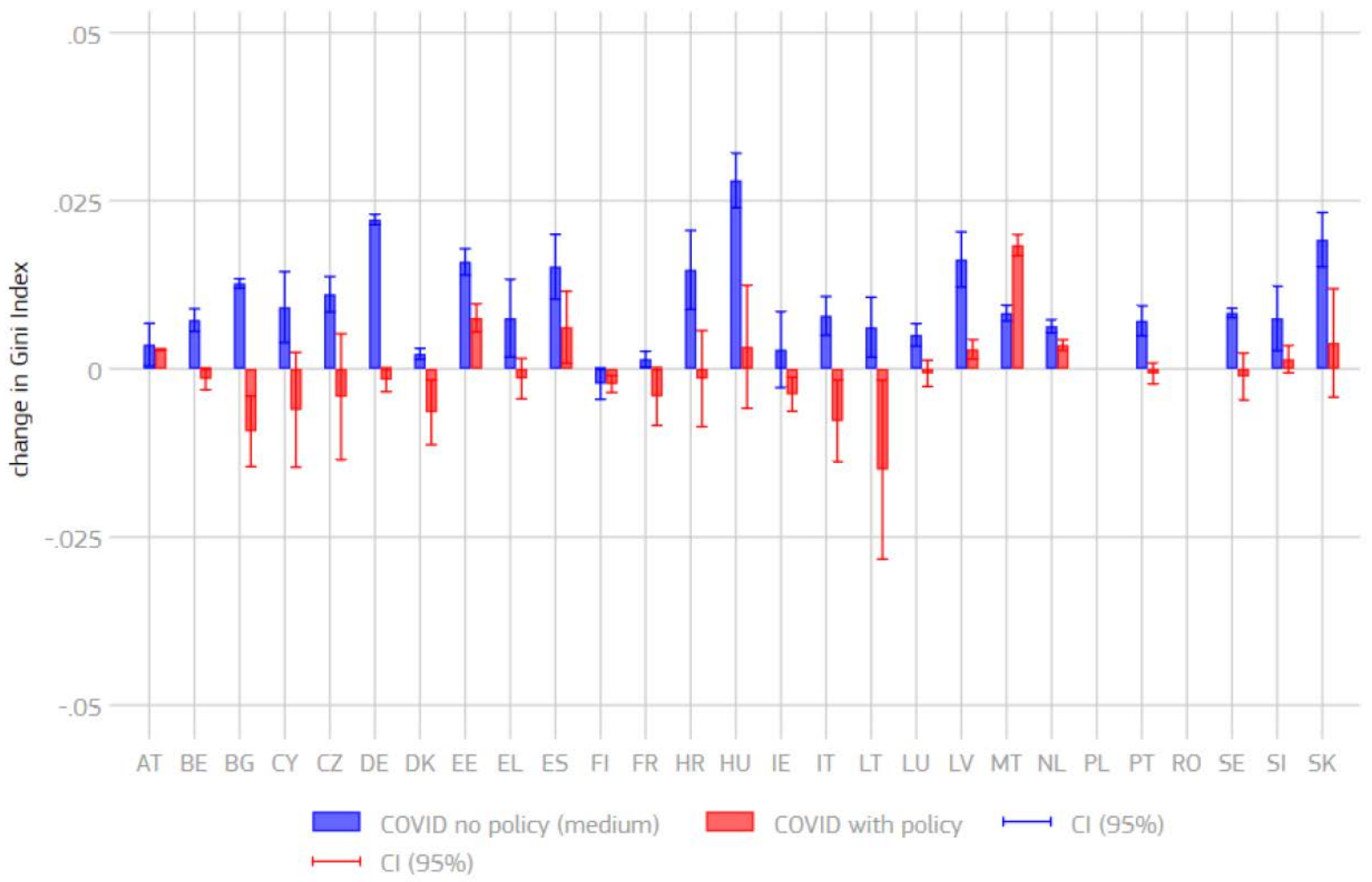

Notes: Figure from Almeida et al. (2020).

This figure shows the change in the Gini coefficient of equivalized disposable income induced by the lockdowns put in place by European countries during the spring of 2020. The authors estimate the changes in GDP and employment induced by lockdown measures and use a micro-simulation model to estimate the effect of these changes on income distribution, under a counterfactual scenario without policy response (blue bars) and under a scenario accounting for actual policy response (red bars). Lines illustrate $95 \%$ confidence interval. 
Figure A.4: Evolution of mean Wealth and Wealth inequalities Post-COVID19 in the UK. Angelopoulos et Al. (2021)
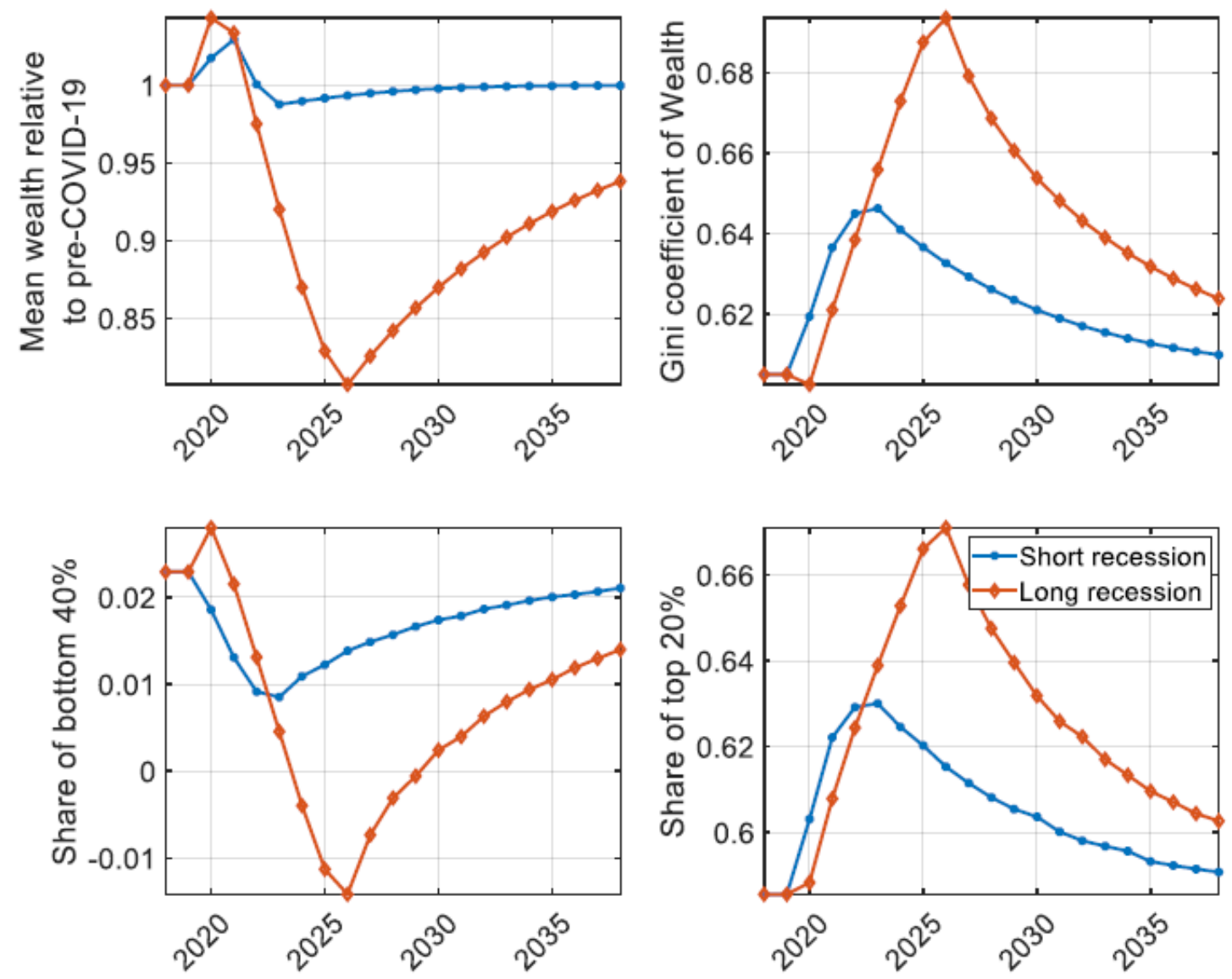

Notes: Figure from Angelopoulos et al. (2021).

The authors calibrate a Bewley model to analyze the effect of the pandemic of wealth accumulation of heterogeneous households in the UK. They consider a short and a lengthy recession, with an increase in labor income risk, a drop in mean income, and consumption restrictions, where recovery is reached in 2024 and 2027 respectively. The model is calibrated using the Wealth and Asset Survey. On the top left panel, mean wealth pre-COVID-19 is normalized to 1 . The two lower panels show the evolution of the share of wealth owned by the bottom $40 \%$ and the top $20 \%$ of wealth distribution. 


\section{A.2 Remote work opportunities as a vector of inequalities}

- Sostero et al. (2020)

The authors use occupational task descriptions to build a classification of occupations in terms of potential for remote work. They apply it to European countries with 2018 data on labor force and estimate that $37 \%$ of employees or dependent contractors ("dependent employment") in the EU are in occupations where remote work is possible.

- Dingel and Neiman (2020)

The authors use surveys describing occupational tasks to build a classification of occupations in terms of potential for remote work. They apply it to the US with 2018 labor force data and estimate that $37 \%$ of US jobs can be worked from home.

- Bick et al. (2020)

The authors use data from a representative survey of over 5,000 respondents to estimate the share of workers that have worked remotely in the US during the spring 2020, keeping track of individual characteristics. They estimate that $35.2 \%$ of the workforce worked from home in May 2020.

- Irlacher and Koch (2021)

The authors use data from the German Qualifications and Career Survey, conducted between 2017 and 2018, to run a Mincer regression and estimate the effect of remote work on wages. Using a rich set of controls (worker and firm characteristics, industry, and region fixed effects), they estimate that people who work from home benefit from a $12 \%$ wage premium. They also investigate regional disparities and show that the poorest regions display smaller potential for remote work.

- Bonacini et al. (2021)

The authors use 2018 employment data from the Italian Labor Force Survey to estimate the consequences of a permanent increase in the feasibility of remote work on the labor income distribution. Using the remote work feasibility index proposed by Barbieri et al. (2020), they classify the population between employees with low and high remote work feasibility. They estimate with unconditional quantile regression the effect of a shift of a 10 percentage points share of employees from the low feasibility level to the high one. They find that it would increase the mean labor income up to $€ 259$ and that employees in the 8th decile of income distribution benefit from the higher wage premium, by about $€ 500$.

- Etheridge et al. (2020)

The authors use data from a representative survey conducted in June 2020 with 3,411 respondents on self-reported productivity of people working from home during the first lockdown period in the UK They estimate that on average, workers report the same productivity as one year before the pandemic. They find that the self-reported productivity of workers at the bottom of the earnings distribution has significantly decreased.

- De Fraja et al. (2020)

The authors assess the effect of the geographic shift of productive activities from office to home, which they call the "Zoomshock," in the UK. They find a strong heterogeneity in the Zoomshock between regions, with a share of residents who can work from home varying between $30 \%$ and $60 \%$.

- Crowley and Doran (2020)

The authors use occupational level data from $\mathrm{O}^{*} \mathrm{NET}$ in Ireland to construct a measure of social distancing potential and a measure of remote work potential. They find higher potential for remote work in the Dublin region and provincial city regions, where economic activity is concentrated. 
- Adams-Prassl et al. (2020c)

The authors use data from a representative survey of 24,924 respondents during the spring of 2020 to estimate the share of tasks that can be done from home within occupations and industries in the UK and in the US.

Figure A.5: Potential for Working From Home in Italy in 2018, By SeCtor AND INCOME

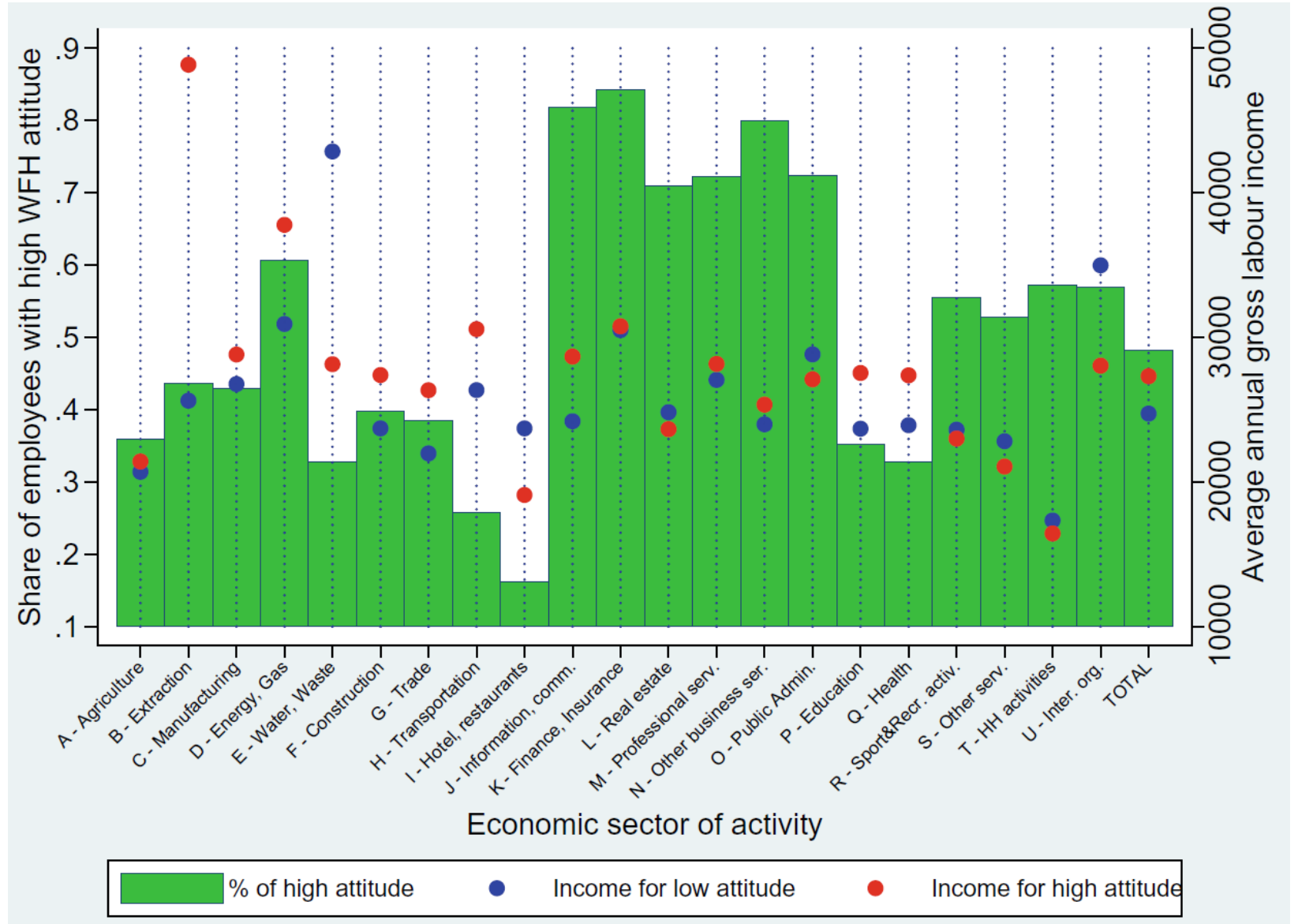

Notes: Figure from Bonacini et al. (2021).

The authors use the index proposed by Barbieri et al. (2020) to measure the feasibility of Working From Home (WFH) of Italian employees, with the 2018 Italian Labour Force Survey. They separate employees between those with high and low WFH attitude. This figure shows the share of employees with high WFH attitude by sector (left scale) and the average gross labor income (right scale) for both groups of employees, by sector. 
Figure A.6: Mean productivity Change Between January and June 2020, in THE UK, BY INDUSTRY AND BY OCCUPATION
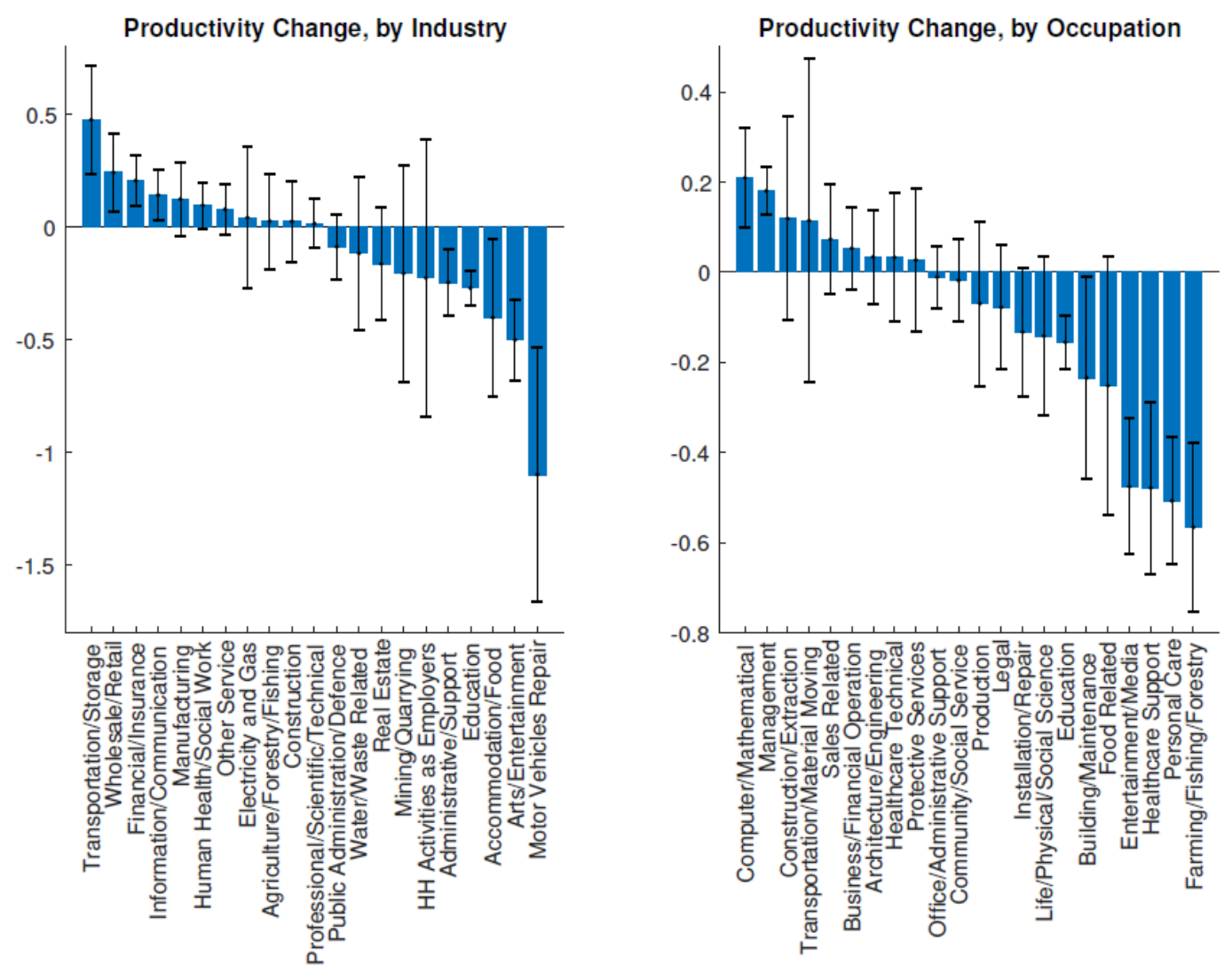

Notes: Figure from Etheridge et al. (2020).

The authors use data from a representative survey performed in June 2020 with 3,411 respondents to estimate the changes in self-reported productivity between January and June 2020 in the UK. A value of 0 indicates that the respondent reports no productivity change. Values are expressed in terms of standard deviation away from 0 . Lines illustrate $95 \%$ confidence intervals.

\section{A.3 Employment loss}

- Piyapromdee and Spittal (2020)

The authors use data from the UK Household Longitudinal Study to evaluate the labor market impacts of the pandemic in the UK. They investigate the change in employment status between February and April 2020 and find that the likelihood of being furloughed or laid off falls along earnings and wealth distribution.

- Adams-Prassl et al. (2020b)

The authors conducted a representative survey on March 25, 2020 on 3,974 respondents to collect employment data and evaluate the labor market impacts of the pandemic in the UK during the spring of 2020. Causes of unemployment were self-reported by the respondents. They find evidence for increased inequality along multiple dimensions: women and less-educated workers suffered disproportionate impacts of the crisis. They also provide evidence for heterogeneous impacts both within and between 
countries, depending on the labor market schemes and ability to work remotely, respectively.

- Li et al. (2020)

The authors use a semi-parametric approach to estimate the impact of the pandemic on Australian income distribution during the spring of 2020. They use the Monthly Longitudinal Labour Force Survey to estimate the probability of dropping out of employment conditional on being employed in the previous period across income quintiles. In April 2020, they estimate the propensity of dropping out of employment in the bottom income quintile was $14.17 \%$ and $2.58 \%$ in the top income quintile.

- Chetty et al. (2020)

The authors build a real-time and granular-level database to keep track of the impact of the pandemic on key indicators in the US. Data from the tracker provides evidence for the differential impact of the pandemic across income groups: high-wage earners recovered much more quickly than their low-wage counterparts. Furthermore, because the US stimulus payments did not lead to substantial increases in employment, they argue that social insurance would be a more appropriate policy remedy during the pandemic. Their economic tracker is publicly available here.

- Pieh et al. (2020)

The authors conduct a representative survey to collect data on the mental health consequences of the pandemic in Austria during the spring of 2020. Considering several measures of depressive symptoms, stress, anxiety, and sleep quality, they found that after four weeks of lockdown, the mental health burden was significantly higher for low-income households.

- Stiglitz (2020)

The authors study a two-sector model with mobility constraints and uncertainties on the depth, duration, and long-term consequences of the pandemic. As labor intensive production becomes more costly with infection risk, the uncertainty on the duration of the pandemic triggers a shift toward automation, reinforcing inequalities.

- del Rio-Chanona et al. (2020)

The authors estimate the supply and demand shock induced by the pandemic in early spring 2020 and analyze the effect on employment and wages in the US. The supply shock is thought of as a labor supply shock and is estimated by constructing a measure of remote work feasibility at the occupation and sector level. The demand shock is estimated using the estimates of the US Congressional Budget Office (2006), aimed at evaluating the effect on an influenza pandemic. Authors aggregate the two shocks and estimate the impact on employment and wages. The authors find that demand and supply shocks have different effects across industries and occupations. Importantly, low wage professions are more impacted by both types of shocks whereas high wage professions are more insulated. 
Figure A.7: Changes in US EMPloyment By WAGE QUARTiles From January to NOVEMBER 2020.

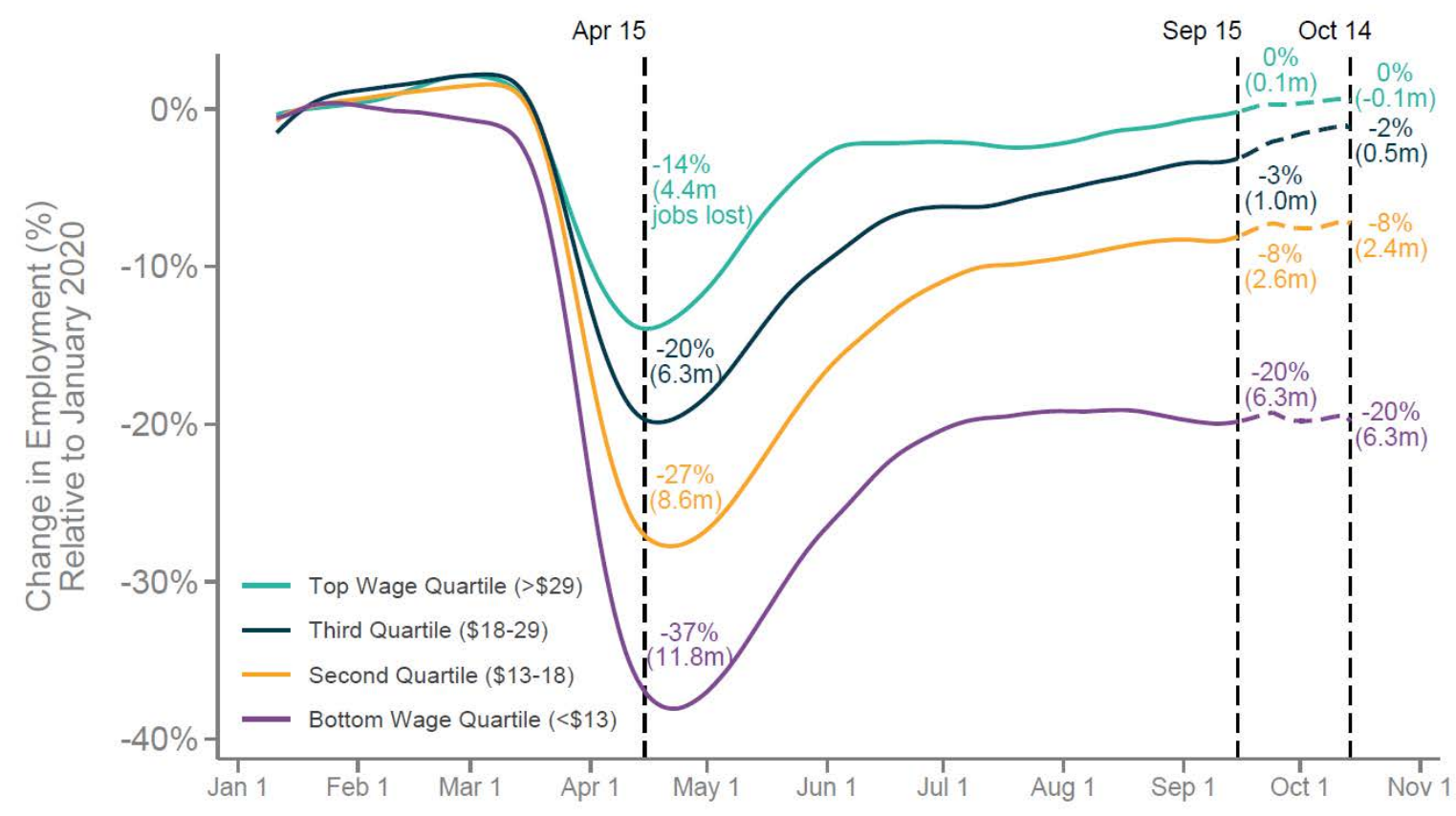

Notes: Figure from Chetty et al. (2020).

This figure shows the changes in employment by wage quartile relative to January 2020. Each quartile is computed based on pre-COVID-19 wage distribution.

\section{A.4 Consumption and savings}

- Andersen et al. (2020)

The authors use daily transaction data in Denmark to estimate the effect of lockdown on consumer spending between January and March 2020. They estimate that overall, aggregate spending decreased by $27 \%$ as compared to a counterfactual situation without COVID-19.

- Hacıoğlu-Hoke et al. (2021)

The authors use high-frequency data from a fintech app on transactions in the UK from January to June 2020 to estimate the change in spending behaviors. They estimate that in April 2020, median expenditure declined by $40 \%$ relative to its 2019 level.

- Bounie et al. (2020)

The authors use high-frequency data from French bank card transactions during the spring of 2020 to evaluate the effect of lockdown on consumption and savings behavior. They estimate that overall, net financial wealth has increased by $€ 45$ billion compared to a counterfactual situation without COVID19. They refer to this increase as "excess savings."

- Cox et al. (2020) 
The authors use US household-level bank account data to estimate the change in spending and savings behavior during the spring of 2020. They estimate that by the end of March 2020, total spending per household had declined by $35 \%$ relative to its 2019 level.

- Falcettoni and Nygaard (2021)

The authors review the literature developed in 2020 on unemployment insurance and stimulus checks in the US and find that there is evidence for these measures decreasing poverty and stimulating the economy.

- García-Montalvo and Reynal-Querol (2020)

The authors use fintech app high-frequency data on transactions in Spain from March to June 2020 to estimate the change in spending behaviors. They estimate that in April 2020, total expenditure declined by more than $40 \%$ relative to its 2019 level.

Table A.1: Patterns of SPEnding Behavior During SPRing 2020 aCross income DISTRIBUTION

\begin{tabular}{ccc}
\hline $\begin{array}{c}\text { Citation } \\
\text { Country }\end{array}$ & $\begin{array}{c}\text { Higher cuts in spending } \\
\text { at the top of the distribution }\end{array}$ & $\begin{array}{c}\text { Steeper return to pre-COVID-19 level of } \\
\text { spending at the bottom of the distribution }\end{array}$ \\
\hline \hline $\begin{array}{c}\text { Bounie et al. (2020) } \\
\text { FR }\end{array}$ & $\begin{array}{c}\text { High-income group } \\
\text { accounts for } 55 \% \text { of } \\
\text { excess savings. }\end{array}$ & $\begin{array}{c}\text { By June, the 2020/2019 expenditure } \\
\text { ratio reached } 1 \text { for high income and } \\
\text { attained } 1.2 \text { for low-income group }\end{array}$ \\
\hline Cox et al. (2020) & $\begin{array}{c}\text { High-income group } \\
\text { accounts for } 50 \% \text { of total } \\
\text { cut in spending. }\end{array}$ & $\begin{array}{c}\text { By May high income spending remains } \\
\text { 20\% below 2019 level while low-income } \\
\text { almost returns to pre-COVID-19 level. }\end{array}$ \\
\hline $\begin{array}{c}\text { García-Montalvo and } \\
\text { Reynal-Querol (2020) }\end{array}$ & $\begin{array}{c}\text { No heterogeneity in } \\
\text { ES }\end{array}$ & $\begin{array}{c}\text { No heterogeneity in spending recovery } \\
\text { across income distribution by June 2020. }\end{array}$ \\
\hline income distribution & High-income group \\
Hacioğlu-Hoke et al. (2021) & accounts for 45\% of total \\
UK & cut in spending. & $\begin{array}{c}35 \% \text { below 2019 level while low-income } \\
\text { spending was 15\% below. }\end{array}$ \\
\hline
\end{tabular}

Notes: In Bounie et al. (2020), households are ranked according to their level of expenditure in 2019. High and low income refer to top and bottom decile respectively. The excess savings refers to the savings accumulated due to the spring lockdown. In Cox et al. (2020) high- and low-income groups refer to top and bottom quartile of 2019 income distribution. In Hacıŏlu-Hoke et al. (2021) these groups refer to households with after-tax income above $£ 40,000$, or below $£ 20,000$ respectively.

\section{A.5 Digital skills and learning opportunities}

- Chiou and Tucker (2020)

The authors use mobile devices data to keep track of physical mobility in the US. They found that in March 2020, people in high-income regions were more likely to stay at home. They show that this correlation is driven by access to high internet speed.

- Ong et al. (2020)

The authors use data from the US Census Bureau's weekly Household Pulse Survey to evaluate the effect of the pandemic on the digital divide in virtual learning, focusing on the fall 2020 semester. They find that low-income households are more impacted, with limited access to computers or internet. 
- Beaunoyer et al. (2020)

The authors analyze the reciprocal effects of the pandemic and the digital divide, arguing that the two phenomena are mutually-reinforcing.

- Lai and Widmar (2021)

The authors use publicly available data on internet performance in the US from December 2019 to June 2020 to evaluate the digital divide along a geographic dimension. They find that rural areas are associated with lower internet speed at the county level.

\section{B Inequalities across sectors and regions}

\section{B.1 Sectoral inequalities}

- Chundakkadan et al. (2020)

The authors use firm-level data from 13 countries (Albania, Chad, Cyprus, Georgia, Greece, Guinea, Italy, Moldova, Niger, Russia, Togo, Zambia, and Zimbabwe) to evaluate the consequences of the pandemic on financially-constrained firms. They use a probit model including the firms' controls, as well as the country and region fixed effects, to estimate the effect of financial constraints on the probability of firm closures and on the probability of worker layoffs.

- Bellucci et al. (2020)

The authors use data on venture capital (VC) investments in 160 countries between 2018 and July 2020. Using difference in difference estimation, they show that the pandemic triggered a significant reallocation of VC flows toward health-related sectors.

- Sherif (2020)

The author uses UK Dow Jones data between Jan. 20 and May 20 to evaluate the effect of the pandemic on the stock market performance of various sectors. The finding suggests that the information technology sector performed significantly better than the market. Conversly, the consumer discretionary sector, which refers to transportation for people, beverages, tourism, and leisure, significantly underperformed in the market. 
Figure B.1: Expenditure CHANGes in France, BEFore AND AFter the SPRING 2020 LOCKDOWN, BY SECTOR

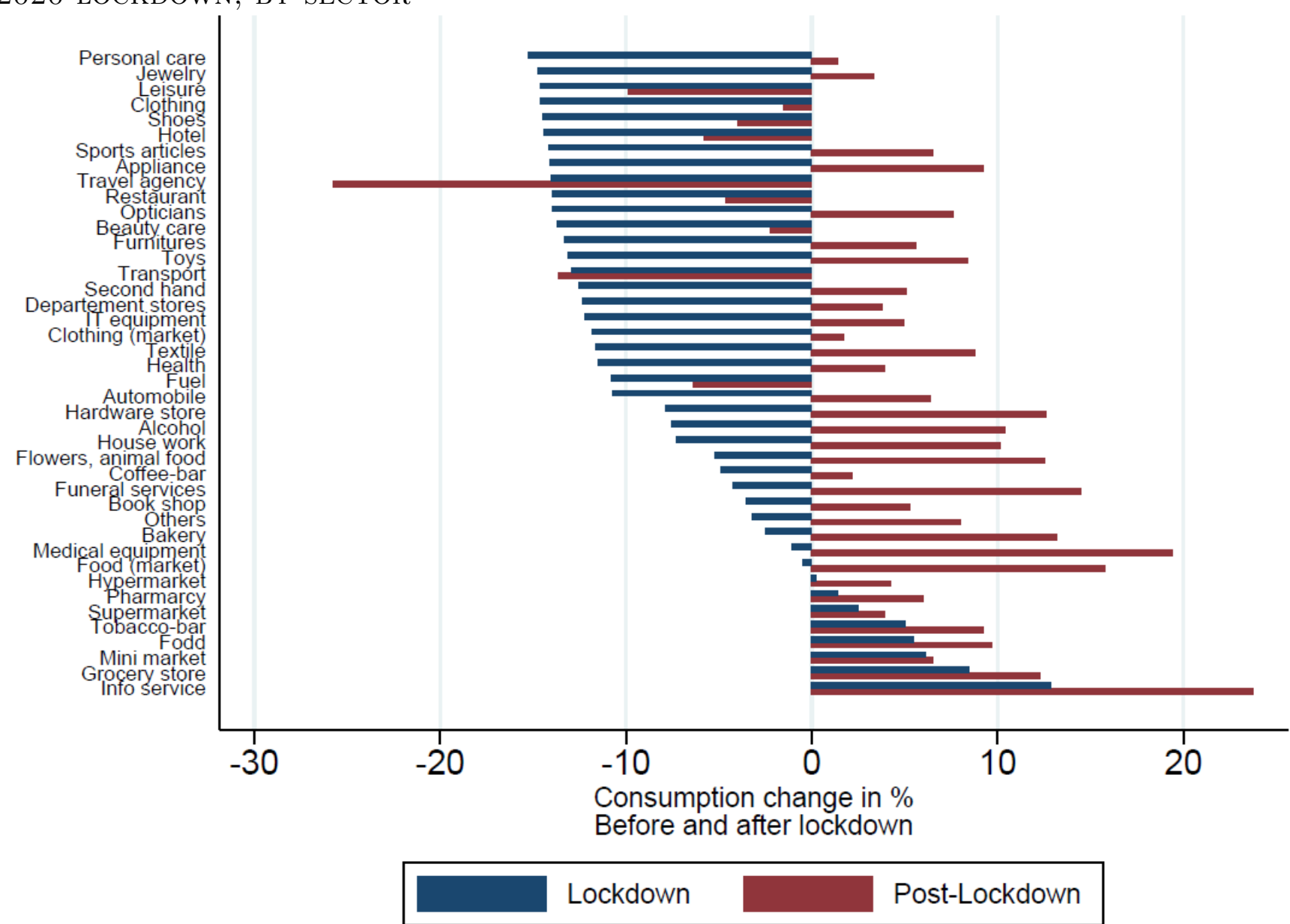

Notes: Figure from Bounie et al. (2020).

This figure shows the evolution of aggregate weekly credit card expenditures in France during the lockdown period (from mid March to mid May 2020, in blue) and post-lockdown period (from mid May to August, in red). Each bar measures the overall losses or gains made during each period as a fraction of annual 2019 expenditures, controlled for seasonality and trend. 
Figure B.2: Percentage Change in Small Business Revenue in the US

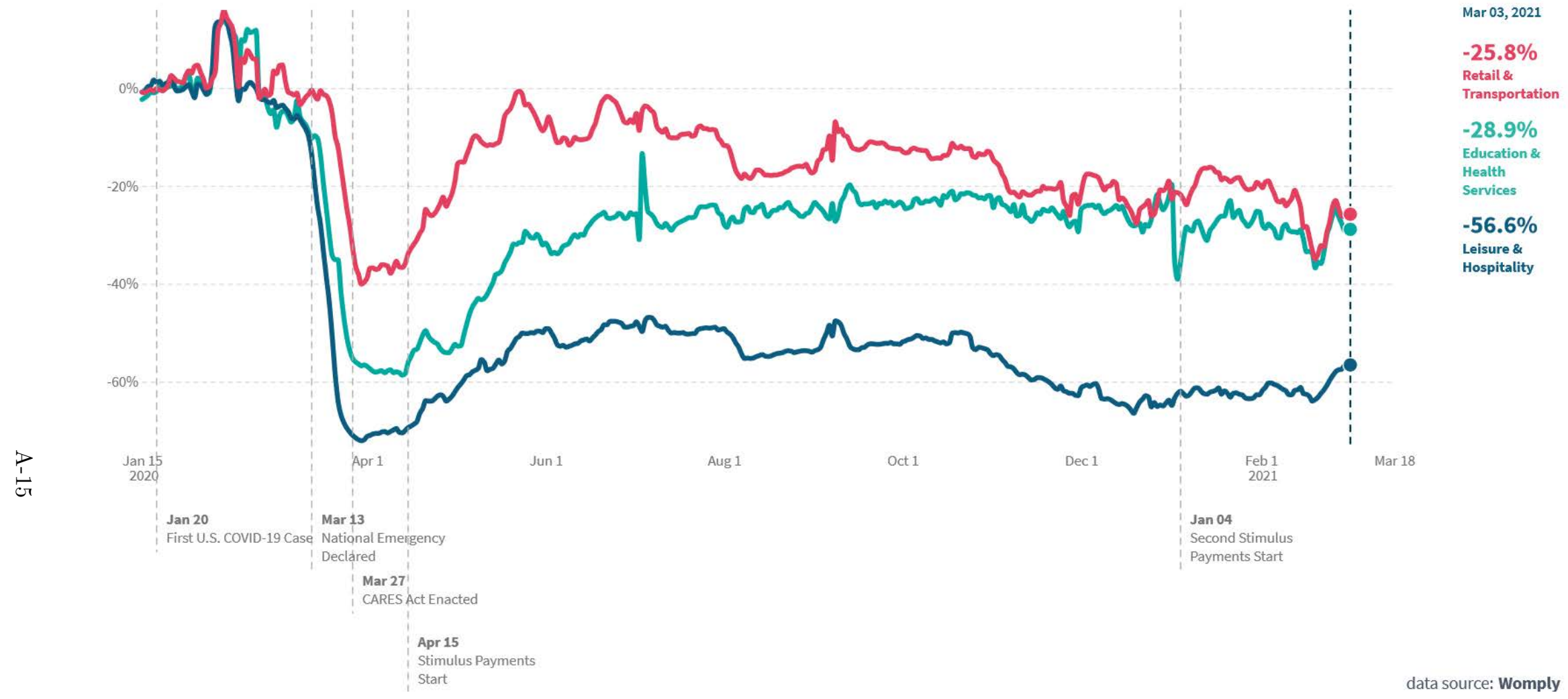

Notes: Figure from the Opportunity Insights Economic Tracker.

This figure shows the evolution of the percentage change in small business revenue in the US from January 2020 to mid March 2021, for retail and transportation sector (in red), education and health services (in green), and leisure and hospitality (in blue). Data on business revenues are seasonally adjusted. 


\section{B.2 Regional inequalities in health impacts and consequences of remote work}

- Weill et al. (2020)

The authors use mobile device location data to measure the changes in human mobility in the US between January and April 2020. Controlling for county fixed effects, they found that mobility declined significantly more in wealthier areas.

- Siddique et al. (2020)

The authors use county and state level data to evaluate the relation between the pandemic and poverty in the US between January and July 2020. Controlling for state fixed effects, they found that at the county level, higher poverty led to higher infection and fatality rates.

- Brandily et al. (2020)

Authors use municipalities level data to evaluate the heterogeneous impact of the pandemic on mortality in France until June 2020. They estimate that mortality due to COVID-19 was twice higher for municipalities in the bottom quarter of the national income distribution than in other municipalities. They show that the higher concentration of occupations involving physical proximity plays a key role, and with poor housing conditions, explains $77 \%$ of the difference between poor and rich municipalities.

- Kapitsinis (2020)

The authors use territorial level data (NUTS 2) to evaluate the uneven spread of the virus between regions in nine EU countries, from January to May 2020. They identify several key factors shaping regional inequalities in terms of COVID-19 mortality, including air pollution, previous health expenditure, the share of elderly, and urbanization rates.

- Ozguzel et al. (2020)

The authors use data from the European Labor Force Survey to evaluate transition to remote work at a regional level in $27 \mathrm{EU}$ countries, Switzerland, Turkey, and the US during lockdown periods. They find a strong heterogeneity in the potential for remote work between and within regions as well as important disparities between urban and rural regions.

- Delventhal et al. (2021)

The authors develop a quantitative model of the Los Angeles metropolitan area to evaluate the effect of a permanent increase in remote work. Their model predicts that more productive workers move to the periphery, reducing congestion and commuting time but also reducing housing prices in core locations. Workers who continue to work on-site stay in core locations. 
Figure B.3: Share of Jobs that CAN POtentially Be Performed Remotely, BETWEEN AND WITHIN COUNTRIES IN EUROPE, 2018

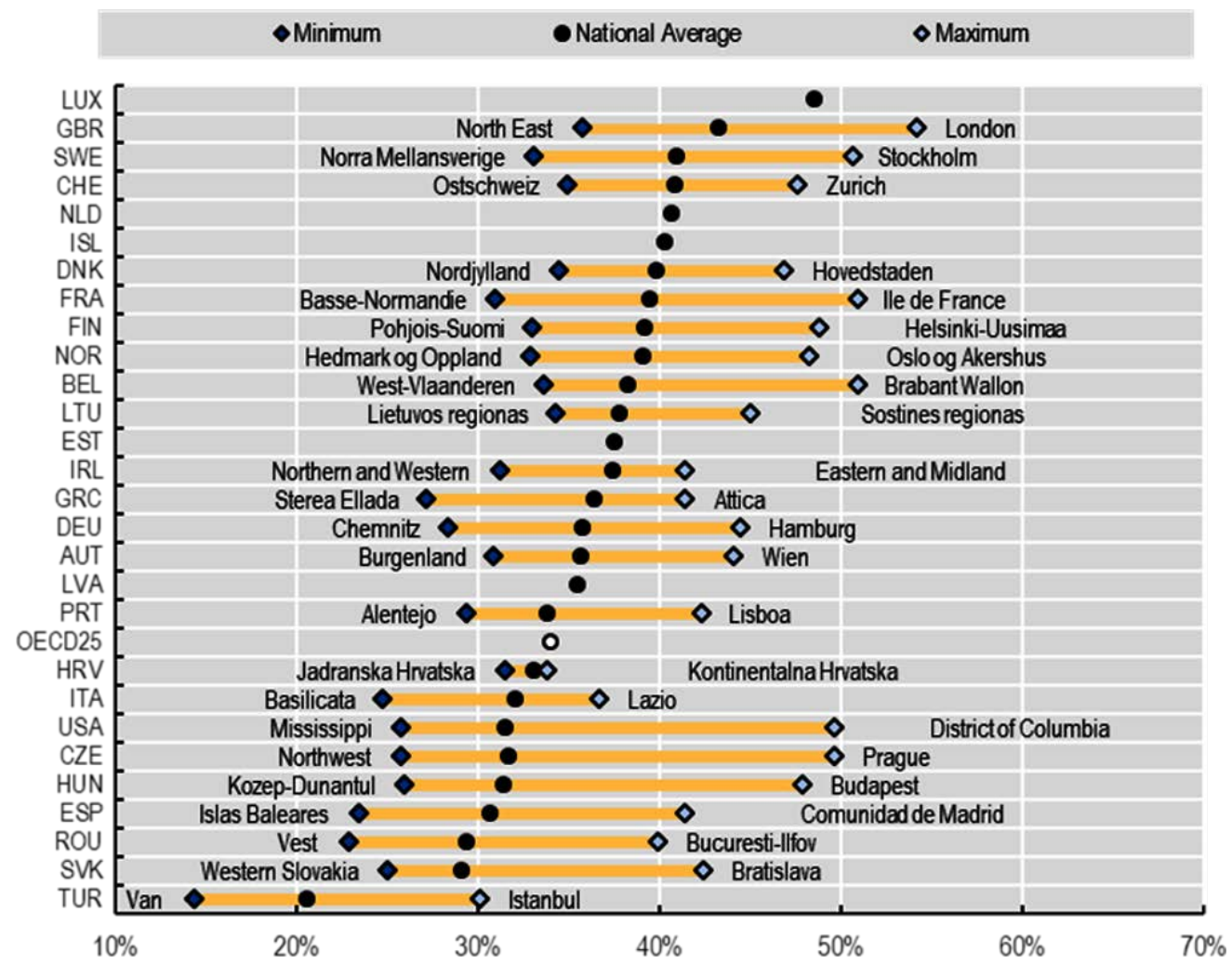

Notes: Figure from Ozguzel et al. (2020).

This figure shows the number of jobs in each country or region that can be carried out remotely as the percentage of total jobs. Countries are ranked in descending order by the share of jobs in total employment that can be done remotely at the national level. Regions correspond to NUTS-1 or NUTS-2 regions, depending on data availability. The authors built a classification of occupations in terms of potential for remote work based on the one proposed by Dingel and Neiman (2020) and applied it to the European Labor Force Survey.

\section{Gender inequality}

\section{C.1 Remote work, working hours and unemployment}

- Reichelt et al. (2020)

The authors want to answer how men's and women's employment status, working hours and working arrangements (main place of work) changed during the pandemic in the US, Germany, and Singapore. The results suggest that women have a 7 percentage points higher likelihood of having experienced a transition to working from home, a 5 percentage points higher likelihood of having reduced their weekly hours by more than 10 , and a 3 percentage points higher likelihood of having transitioned to unemployment since January (see Figure C.1). Additional analyses reveal that gender differences are not due to differences in labor market participation across countries. Gender differences in the transition to working from home and in reducing hours mostly hold, even after accounting for male-female differences in socio-demographics, income, and pre-COVID employment relations. Gender differences in transitions to unemployment, however, disappear, which can mostly be attributed to women having worked part-time and having had lower incomes in January and factors associated with a higher risk 
of becoming unemployed.

- Farre et al. (2020)

The authors investigate how the social distancing measures and stay-at-home orders affected the gender inequality in employment and time devoted to childcare and household chores in Spain. For this purpose, they ran a survey on a representative sample of the Spanish population aged $24-50$ in early May 2020. They find that previously-employed women are significantly more likely to be furloughed and unemployed than men. Also, women were 6.5 percentage points more likely than men to work from home during the lockdown. To assess changes in the distribution of unpaid work at home such as childcare and housework, the authors focus on two-parent households of opposite sex with children. They find that even though men increased their participation in housework and childcare, most of the burden still fell on women, who were already doing most of the housework before the lockdown, and who on average spend around 10 hours more per week on childcare compared to fathers. Overall, they conclude that the COVID-19 crisis appears to have reinforced gender inequalities in both paid and unpaid work in the short-term in Spain.

- Mongey and Weinberg (2020)

The authors categorize occupations in the US by a measure that captures the likelihood that jobs can be conducted from home (Dingel and Neiman (2020)), as well as a measure of low personal proximity in the workplace. The former relates to how well work can be done under social distancing policies; the latter relates to how quickly occupations might come back offline. The results suggest that individuals in occupations that score highly in terms of work-from-home and occupations with high personal proximity are more likely to be women. This suggests that the employment effects of broad social distancing policies may be less severe for women who work from home, but later integration into the economy may be more difficult due to the high share of women who work in occupations with high personal proximity.

- Bonacini et al. (2021)

The authors use data from the from the survey on the Participation, Labor and Unemployment (PLUS), which provides reliable statistics on labor market phenomena and has 45,000 individuals, and merge it with the 2013 Italian Survey of Professions (ICP), which reports information on the nature and content of the work for about 16,000 Italian workers. Adopting the work-from-home feasibility index from Barbieri et al. (2020) the authors apply it to the detailed data set and find that women experience 5 percentage points higher feasibility to work from home than men in Italy.

- Del Boca et al. (2020)

The authors use a representative sample of 800 Italian working women interviewed in April and July in 2019 and April 2020. The questionnaire gathers rich information on changes in the respondents' employment status, working hours, childcare, income, and satisfaction regarding their work and family during the pandemic. By employing linear probability models, the authors confirm that Italian women have higher likelihood to have continued working from home during the pandemic compared to Italian men.

- Hatayama et al. (2020)

The authors use skill surveys in 53 countries to estimate residents' amenability to work from home. The results suggest that across most countries, women are more amenable to working from home than men. This is because they are less likely to have jobs intensive in physical/manual work than men.

- Adams-Prassl et al. (2020b)

Using real time surveys, the authors document that women were 7 and 5 percentage points more likely to lose their jobs (compared to men) in the US and UK, respectively, while in Germany, gender does not predict job loss with statistical significance. They found that the share of tasks that can be done from home within occupation and industry is a powerful predictor of the share of workers that lost their jobs, as it alone can explain more than $50 \%$ of the variation in job loss due to COVID-19 across occupations in the US, the UK and Germany (figure C.4). Additionally, workers with permanent, salaried fixed 
hour contracts were less likely to be affected compared to workers who were on temporary contracts, non-salaried and whose hours varied (and latter groups better describe women).

- Sevilla and Smith (2020)

The authors collected real-time data for 4,250 respondents aged 18 - 60 in the UK in May 2020. They confirm the results from Adams-Prassl et al. (2020b) and show that women in the UK are less likely than men to still be working ( $19.7 \%$ of men vs. $13.5 \%$ of women), more likely to be furloughed $(18.6 \%$ for men vs. $19.7 \%$ for women), and more likely to be not working ( $28.7 \%$ of men vs. $35.3 \%$ of women).

- Oreffice and Quintana-Domeque (2020)

The authors use an online sample of approximately 1,500 respondents, representative of the UK population along the dimensions of age, sex, and ethnicity. They show that women are 4.2 percentage points more likely than men to have lost their jobs due to COVID-19. They argue that the main driver of the results is the fact that women are concentrated in sectors which are disproportionately affected by the crisis.

- Kristal and Yaish (2020)

Based on a longitudinal survey of 2,040 adult Israeli men and women, who were employed or selfemployed in the first week of March 2020, the authors study the impact of the pandemic on the Israeli labor market. Results are in line with other countries and confirm that women's employment has been more negatively affected than men's. The explanations they offer are that a high fraction of women were employed in low- and medium-wage jobs before the pandemic, more Israeli women than men have non-standard employment relations, fewer women hold managerial positions in the labor market, women are more likely than men to work in occupations and sectors of the economy that were hit the hardest, and mothers of young children are more likely than fathers to leave employment and care for the children.

- Immel et al. (2021)

Using a self-designed panel survey of German households, authors investigate how the spread of the COVID-19 pandemic has affected the German population economically, socially, and emotionally. The survey was carried out in: i) June 2020, during a period of low infection rates and relaxing restrictions; ii) October 2020, at a time when infection rates rose sharply; iii) and November 2020, shortly after new restrictions on public and private life were introduced. The final sample comprises 30,000 representatively-selected individuals aged 18 and above. First, authors apply common factor analysis in order to identify how people are affected by the pandemic, based on common variation in these items. Second, they regress the retrieved factors on a number of socio-demographic characteristics to draw conclusions about the differential impact of the pandemic by population groups. The results of the factor analysis suggest that the consequences the pandemic has on people's lives can be summarized by two common factors: i) factor related to respondents' concerns that they or their family members get infected (concern about Infection); and ii) factor related to burdens due to restrictions on public life and contacts, job loss, a decrease in household income, and financial concerns (socio-economic strain). They find that women are more affected by the pandemic than men. In all three survey waves, they are more concerned about infections and also suffer from the adverse socio-economic consequences of the pandemic to a greater extent (the indicator for socio-economic strain is, $0.09-0.10$ standard deviations larger for women than it is for men).

\section{C.2 Childcare and housework}

- Adams-Prassl et al. (2020b)

Using real-time surveys, the authors ask respondents in the US, the UK, and Germany about the time spent on active childcare and homeschooling. After restricting the sample to individuals with children and who report working from home, the authors find that women spend a lot more time on active childcare and homeschooling than men. On average, that is around 1.5 hours per day more than men (Figure C.5). 
- Alon et al. (2020)

The authors combine several data sets for the US and find that among the couples with children who both work full time, women provide about $60 \%$ of childcare hours. When children are younger, the share is even higher. They also argue that it is likely that the situation will persist throughout the crisis, as the factors which initially led to this arrangement (e.g., relative income, relative bargaining power, and influence of traditional social norms and models) will continue to hold.

- Sevilla and Smith (2020)

The authors collect real-time data on daily lives of UK families with young children. They document that women are doing the majority of the childcare, irrespective of their employment. On average, women have been doing 30.3 additional hours of childcare per week, compared to 19.4 hours done by men. The amount of additional childcare provided by men is very sensitive to their employment status - the allocation is closer to equal in households where men are working from home or where they have been furloughed or lost their jobs.

- Andrew et al. (2020)

The authors use real-time data on 4,915 parents in England who live with at least one child in one of eight different school years (which roughly corresponds to having a child between 4 and 15). They note that mothers are spending much longer hours in childcare and housework than their partners, and that they are spending a larger fraction of their paid work hours having to juggle work and childcare. They conclude that gender differences in the allocation of domestic work cannot easily be explained by differences in employment or earnings.

- Dijst et al. (2021)

The authors focus on a survey of 344 individuals in Luxembourg who are in stable relationships and have a child younger than 13 years old. By comparing the time spent on nine activities per week (working outside, working at home, housework, childcare, commuting, leisure, helping, nothing, and other) they show that women have, on average, spent 12 hours per week more than men on childcare.

- Hupkau and Petrongolo (2020)

The authors use the COVID-19 supplement to the Understanding Society longitudinal survey in the UK. They also find that women shouldered a higher share than men of the increased childcare needs (9.5 extra hours for women as opposed to 6.9 extra hours for men, Figure C.6).

- Oreffice and Quintana-Domeque (2020)

The authors collected new data on mental well-being, perceptions, employment, health, and behaviours via an online survey of 1,500 respondents in the UK. The authors find that between February and June 2020, women decreased their working hours, but increased housework and childcare much more than men. These gender differences are not driven by differences in age, ethnicity, education, family structure, income in 2019, current employment status, place of residence or living in rural vs. urban areas.

- Hipp and Bünning (2020)

The authors use three waves of an online survey conducted between March and August 2020. They find that parenthood might be a driver of increased gender inequality during COVID-19 in Germany. Parents were more likely than non-parents to work fewer hours during the pandemic than before, and mothers were more likely than fathers to work reduced hours once lockdowns were lifted. Moreover, mothers shouldered more of the childcare work than fathers did, while the division of the remaining housework was unchanged.

- Zoch et al. (2021)

The authors use novel data from two panel surveys of the National Educational Panel study and its supplementary COVID-19 online survey in Germany. They examine the short-term consequences for care arrangements among working parents, who were affected by the school and nursery closures in Germany. The study finds that mothers continue to play a key role in the care-arrangements during 
the pandemic, and that about one-third of families relied exclusively on maternal care, compared to $4-6 \%$ of families which relied exclusively on paternal care.

- Del Boca et al. (2020)

The authors investigate the effect of COVID-19 on work, housework, and childcare arrangements of working women and their male partners in Italy. They use a representative sample of 800 Italian women interviewed in April and July 2019 and in April 2020. Results indicate that changes to the amount of housework done by women during the lockdown do not seem to depend on their partners' working arrangements. With the exception of those continuing to work at their usual place of work, all of the women surveyed spend more time on housework than before. In contrast, the amount of time men devote to housework does depend on their partners' working arrangements: men whose partners continue to work at their usual workplace spend more time on housework than before. Men and women have reacted differently to the changing circumstances, with women increasing the amount of time they spend on both the housework and childcare. The only areas where men have started spending more time are in childcare and homeschooling; they have not contributed more time to doing the housework.

- Fodor et al. (2020)

The authors use data collected in May 2020 in Hungary with a sample size of 1,900 adults, representative along the dimensions of gender, age, education, type of settlement and administrative regions. They investigate the impact of COVID-19 on the gender division of childcare work and conclude that women's contributions grew significantly more than men's and the gap between men and women has increased in absolute work hours by close to 5 hours for women.

- Zamarro and Prados (2021)

Using rich tracking survey data collected every two weeks during the first four months of the pandemic in the US, the authors investigate how fathers and mothers cope with the childcare provision and associated psychological distress levels. They find that the increased need for childcare has put a strain on working parents of both genders, but overall, mothers have been carrying a heavier load on the provision of childcare during the COVID-19 crisis than fathers. Mother are more likely than fathers to be the sole provider of care for their children, to have reduced their working hours, or to have left employment. Finally, the authors also observe a small but new gap in psychological distress that emerged between mothers and women without school-age children in the household in early April. The gap seems to be driven by higher levels of psychological distress reported by mothers of elementary school-age and younger children.

- Deryugina et al. (2021)

The authors investigate the effects of COVID-19 disruptions on the gender gap in academia. They administer a global survey to a broad range of academics across various disciplines to collect nuanced data on the respondents' circumstances, such as a spouse's employment, the number and ages of children, and time use. The authors use a difference-in-differences approach to estimate the effects of COVID-19 disruptions on how academics allocate their time on a typical workday. They find that female academics, particularly those who have children, report a disproportionate reduction in time dedicated to research relative to what comparable men and women without children experience. Both men and women report substantial increases in childcare and housework burdens, but women experienced significantly larger increases that men did. Overall, women with children lose about an hour of research time per day more than childless men do. Men with children lose 30 minutes of research time more than men with no children. Importantly, the widening of the male-female research time gap is driven by the presence of at least one child in a family, but not so much by the number of children.

- Petts et al. (2021)

The authors use a data from a novel survey of US parents collected in late April 2020. The individuallevel survey (i.e., participants reported on both themselves and their partners) contained questions about labor force participation, domestic supports, and parents' division of labor both before (i.e., prior to March 11, 2020) and during the first part of the pandemic (i.e., in late April 2020). They 
consider whether the loss of childcare and engagement in homeschooling are associated with mothers' and fathers' employment status and work hours during the pandemic. They find that mothers who did not have their children in care and those who lost more than 40 hours of weekly care had significantly greater odds of leaving their jobs compared to those who lost less than 10 hours of care. Overall, as expected, mothers are at a greater risk of losing their job during the early pandemic when they lose a substantial number of nonparental care hours and when they are involved in homeschooling activity, whereas fathers' employment is less affected by the loss of nonparental care.

- Boll et al. (2021)

The authors investigate the opposing claims of widening/closing the gender gap in parental childcare during the COVID-19 pandemic in Germany. For that purpose, they use unique monthly panel data from the Institute for Employment Research (IAB) covering the immediate post-lockdown period from June to August 2020. Results suggest a slight shift toward a more egalitarian division in June that faded out in subsequent months. Starting from a fairly "traditional" pre-pandemic childcare division, the lockdown stimulus was not nearly strong enough to level the playing field. They conclude by saying that the shift emerged out of necessity rather than opportunity, which makes it likely to fade once the necessity vanishes, thereby seeing parents return to their initial childcare arrangements.

\section{C.3 Mental health}

The COVID-19 crisis has not only affected women's professional life, but also their work-life balance and well-being. Thus far, the studies have documented a stark reduction in women's well-being compared to men. Women seem to be more worried and pessimistic about the current situation; they also report being more lonely because of social distancing measures and separation from family, friends, and colleagues. Women also feel much more anxious, and overwhelmed with childcare and housework, and have a distorted work-life balance.

- Adams-Prassl et al. (2020a)

The authors document the impact of state-wide stay-at-home measures on mental health, using real time surveys in the US. They show that the lockdown measures have lowered mental health by 0.085 standard deviations, and that this large negative effect is entirely driven by women. This also means that the existing gender gap in mental health has increased by $66 \%$. The explanation for this finding is not clear.

- Oreffice and Quintana-Domeque (2020)

The authors explore the effect of lockdown on mental health in the UK and find that women's mental health in mid-June 2020 was worse than men's along several dimensions: general anxiety disorder, depression, anxiety attacks, and loneliness.

- Banks and Xu (2020)

The authors confirm the results for the UK using the 12-item Generalised Health Questionnaire (GHQ12) measure of mental health, distress, and well-being and conclude that the effects of COVID-19 on mental health are substantial and greater for women.

- Etheridge and Spantig (2020)

The authors document twice as large a decline in mental well-being for women compared to men in the UK after the onset of the COVID-19 pandemic. They seek to explain this gender gap by exploring gender differences in family and care responsibilities, financial and work situations, social engagement, health situations, and health behaviors. Differences in family and care responsibilities play some role, but most of the gap is explained by social factors. Women reported having more close friends before the pandemic than men and increased loneliness after the pandemic's onset. Other factors are similarly distributed across genders and do not play a significant role.

- Czymara et al. (2020)

The authors confirm that women are much more worried about social contact and childcare compared 
to men, who are most worried about paid work and economy. Another report from Switzerland demonstrates that women have more difficulty processing the pandemic than men.

- Brülhart and Lalive (2020)

The authors use helpline calls in Switzerland to measure psychological and social suffering in the population at a daily frequency. They find that women call the helpline twice as much as men.

- Yamamura and Tsutsui (2020)

The authors document that COVID-19 has a stronger impact on women than men in Japan because women feel more anxiety and fear due to the on-going situation.

- Gao and Sai (2020)

The authors share personal reflections on how COVID-19 pandemic affects the working lives and wellbeing of single female academics who live alone in the UK. They say that "spending almost all time alone aggravates feelings of disconnectedness and loneliness" (p. 757).

Figure C.1: Gender differences in COVID-Related Changes in labor market outcomes in the US, Germany and Singapore. Reichelt et Al. (2020)

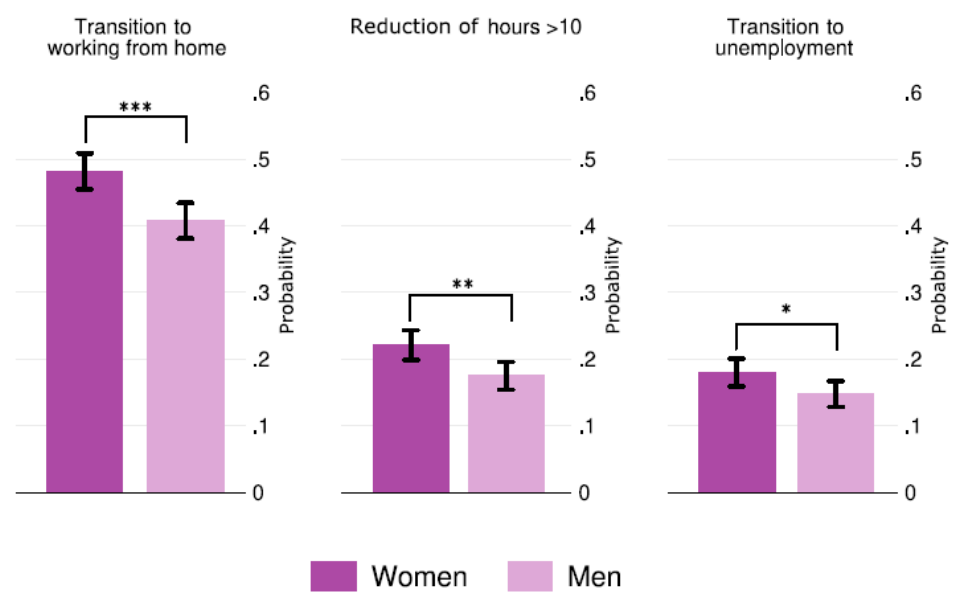

Notes: First dependent variable is "transition to working from home" which is presents whether the respondents transitioned to working from home between January 2020 and the time of the interview (May or June 2020). Second dependent variable "reduction of hours $>10$ " stands for whether the respondents experienced a significant reduction in working hours, meaning a reduction of at least 10 hours per week compared to their working hours in January 2020. Lastly, dependent variable "transition to unemployment" assesses whether the respondents have lost their fullor part-time employment since January 2020. Main independent variable for this analysis is the respondent's gender. $95 \%$ confidence intervals, survey weights used $N=2,589,{ }^{*} p<0.05 ;{ }^{*} p<0.01 ;{ }^{*} *{ }^{*} p<0.001$. 
Figure C.2: Gender egalitarian attitudes. Reichelt et Al. (2020)

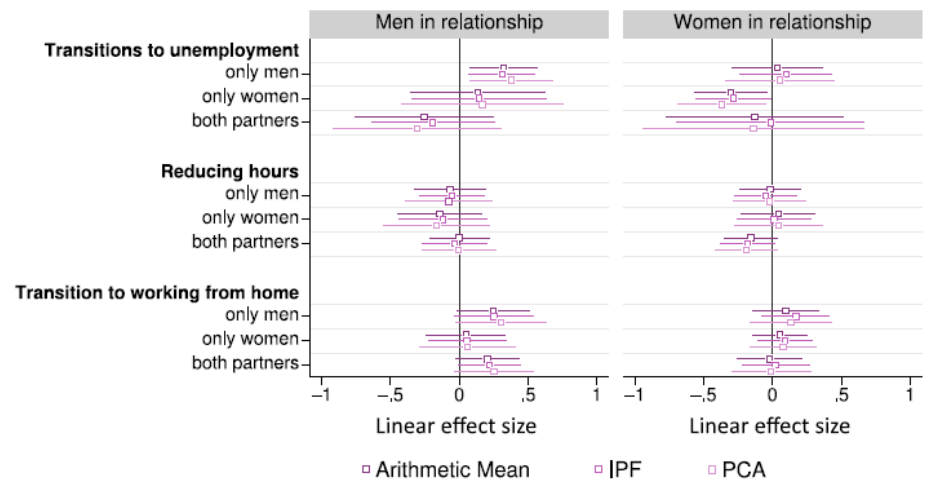

Notes: The authors assess whether COVID-19-related changes in transitions to unemployment, reduction in working hours, or transitions to working from home of respondents and their partners are associated with men's and women's gender-role attitudes. The graph shows estimates for the relationship between the respondents' and/or their partners' transitions on all three measures for gender-role attitudes (based on the arithmetic mean, iterated principle factor analysis (IPF), and principal component analysis (PCA)). Bars around the point estimate show the $95 \%$ confidence intervals for each estimate. Sample conditioned to respondents who worked full- or part-time in January 2020 and whose cohabiting partners worked full- or part-time in January. Survey weights were used; bars signify $95 \%$ confidence intervals.

Figure C.3: Percentage of Working WOMen And their Partner By Working ARrangement DURing the COVID-19 Emergency In Italy. Del Boca et Al. $(2020)$

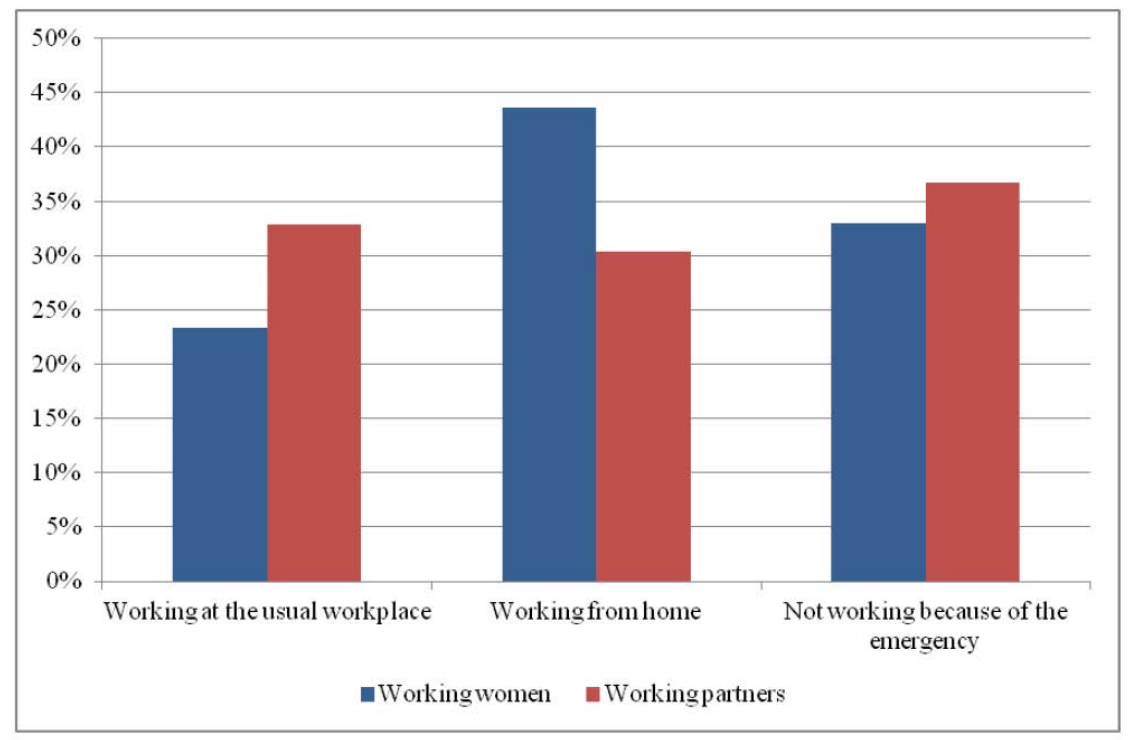

Notes: Figure presents the working arrangements of working women and their partners during the COVID-19 emergency in Italy. $N=520$. 
Figure C.4: Job loss probability to COVID-19 By the Percentage of tasks That CAN BE DONE From home in the US, the UK, And Germany. Adams-Prassl ET AL. (2020B)
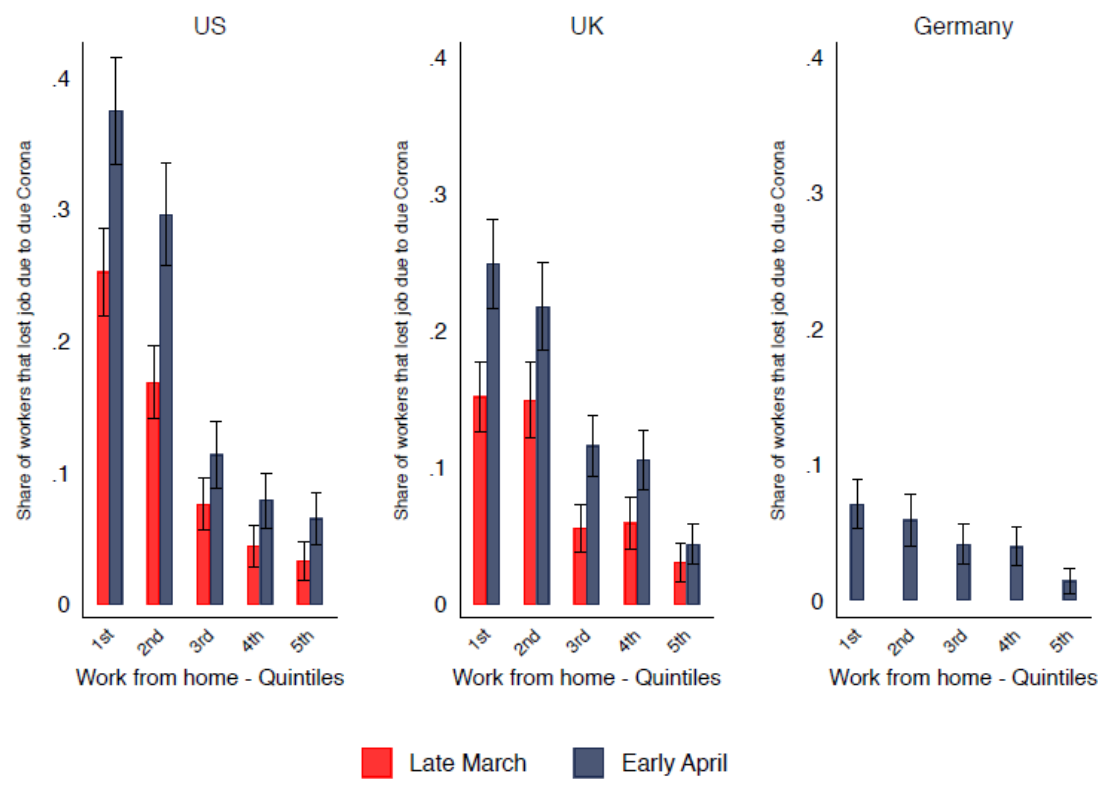

Notes: The figure displays the percentage of people who lost their jobs due to the coronavirus outbreak by the percentage of tasks respondents report being able to do from home (summarized into quintiles represented on the x-axes). The thin black bars represent the $95 \%$ confidence intervals. The figure shows the share of individuals who were in paid work four weeks before data collection and who lost their jobs due to COVID-19.

\section{Inequalities in education}


Figure C.5: Hours SPENT ON A "TYPICAL" WORK DAY DURING THE PAST WEEK ON ACTIVE CHILDCARE AND HOMESCHOOLING IN THE US AND THE UK. AdAMS-PRASSL ET AL. (2020B)
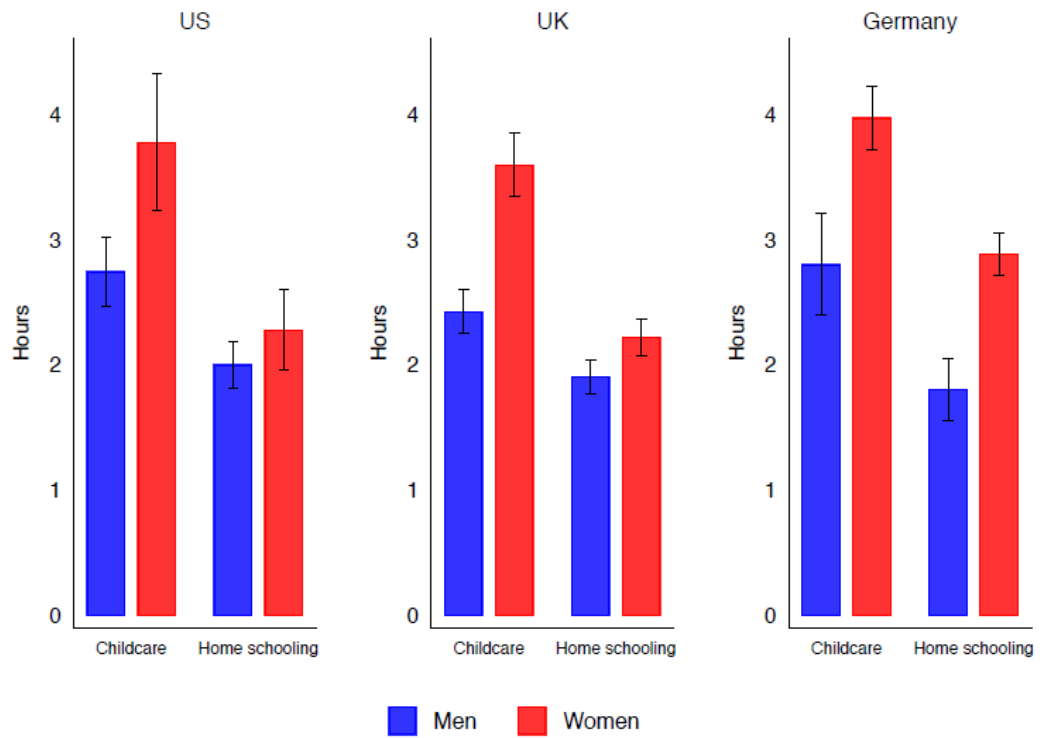

Notes: The figure shows average number of hours that men and women reported spending on childcare and homeschooling. The authors restrict the sample to individuals with children who report working from home, and whose answers to the time use questions combined to not exceed 24 hours. The thin black bars represent the $95 \%$ confidence intervals. 
Figure C.6: Gender Gaps in HOUSEWORK HOURs, BeFore AND DURing COVID-19 in the UK. Hupkau And Petrongolo (2020)

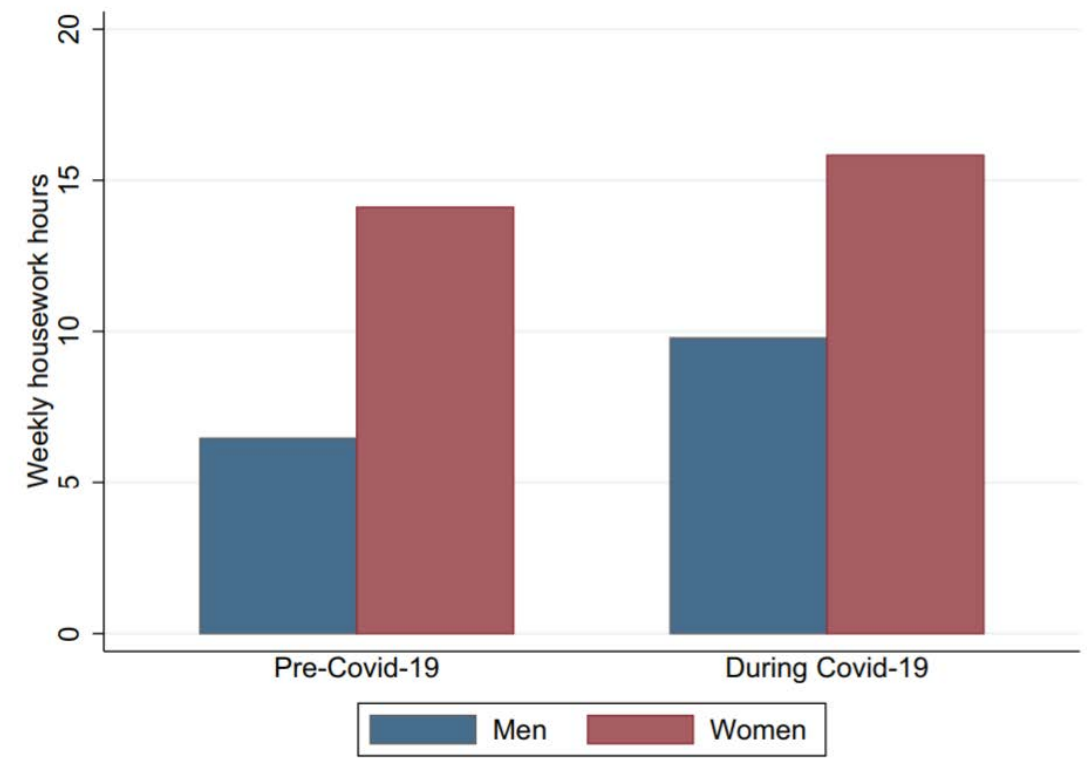

Notes: The bars show usual weekly hours spent on housework before COVID-19 (2016 - 2017) and during COVID-19 (April - May 2020). Sample: men and women living as a couple. $N=10,643$.

Figure D.1: ACtivities of Students With LOW And High test SCORES Before AND During the school Closures in Germany. Grewenig et Al. (2021)

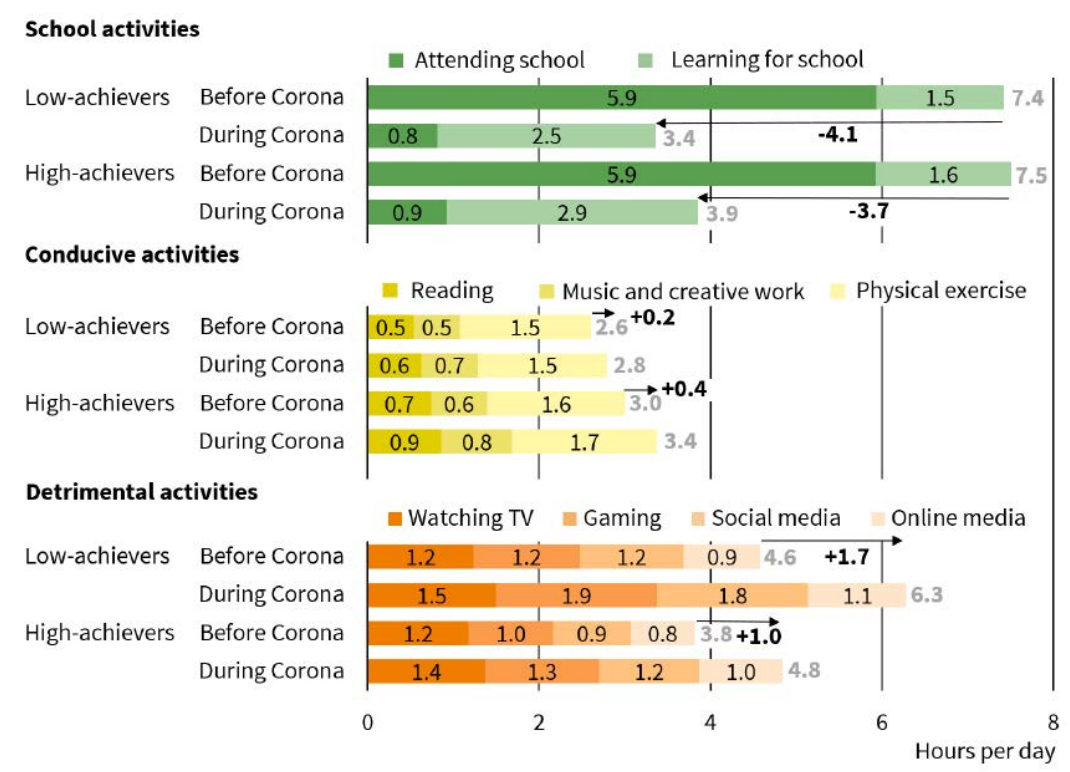

Notes: The figure shows average hours spent on different activities on a typical workday, as reported by students. "During Corona" is a period of school closures due to COVID-19. "Before Corona" stands for a period before the school closures. Students with low versus high test scores are defined as students with an average grade in mathematics and German below versus at-or-above the median for their respective school type. 
Figure D.2: Students' WeEkly EFFort For SCHOol MATters IN SWitzerland, Austria, And Germany. Huber and Helm (2020)

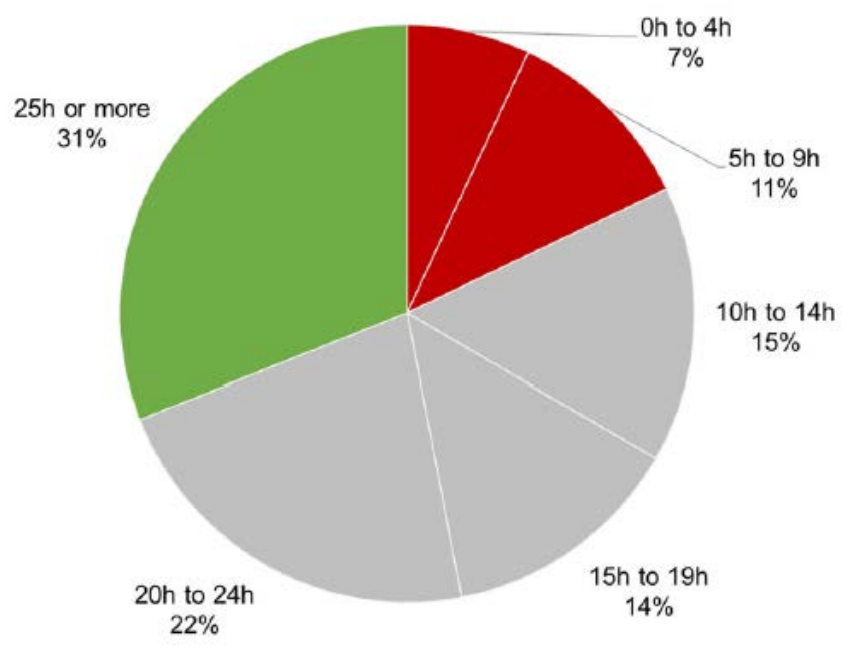

Notes: This figure shows the number of hours spent each week on school matters, as reported by students in Switzerland, Austria and Germany. $13 \%$ of the students are $6-12$ years old, $32 \%$ are $13-15$ years old and $55 \%$ are 16 - 20 years old. $N=2.063$.

Figure D.3: Technical CAPACities For Web-BASEd Formats By COUntry. Huber AND HELM (2020)

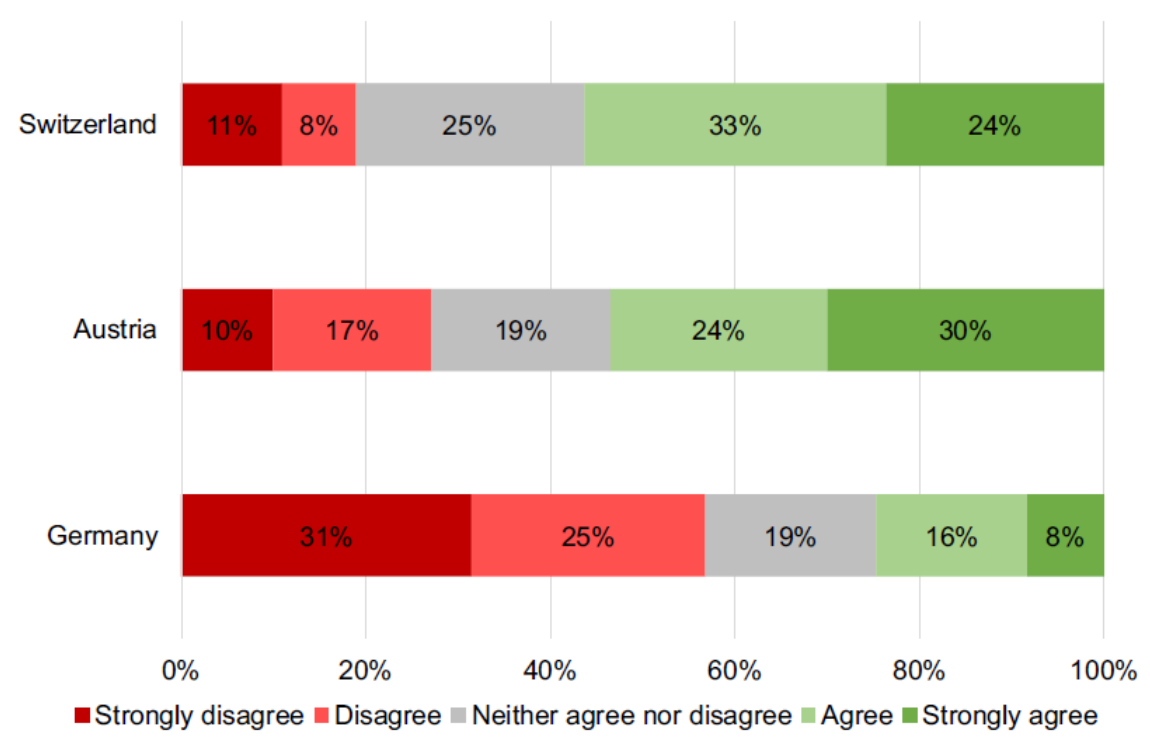

Notes: The figure represents the answers by school staff to the question whether technical capacities in the school are sufficient for web-based formats. The school staff are distributed according to school level as follows: $5 \%$ from kindergartens, $24 \%$ from primary schools, $35 \%$ from lower secondary schools, $21 \%$ from upper secondary schools, $11 \%$ from vocational, schools and $5 \%$ from other schools. 
Figure D.4: Estimates of LEARNing LOSS FOR THE Whole SAMPLE AND BY SUBGroup And test in the Netherlands. Engzell ET AL. (2020)

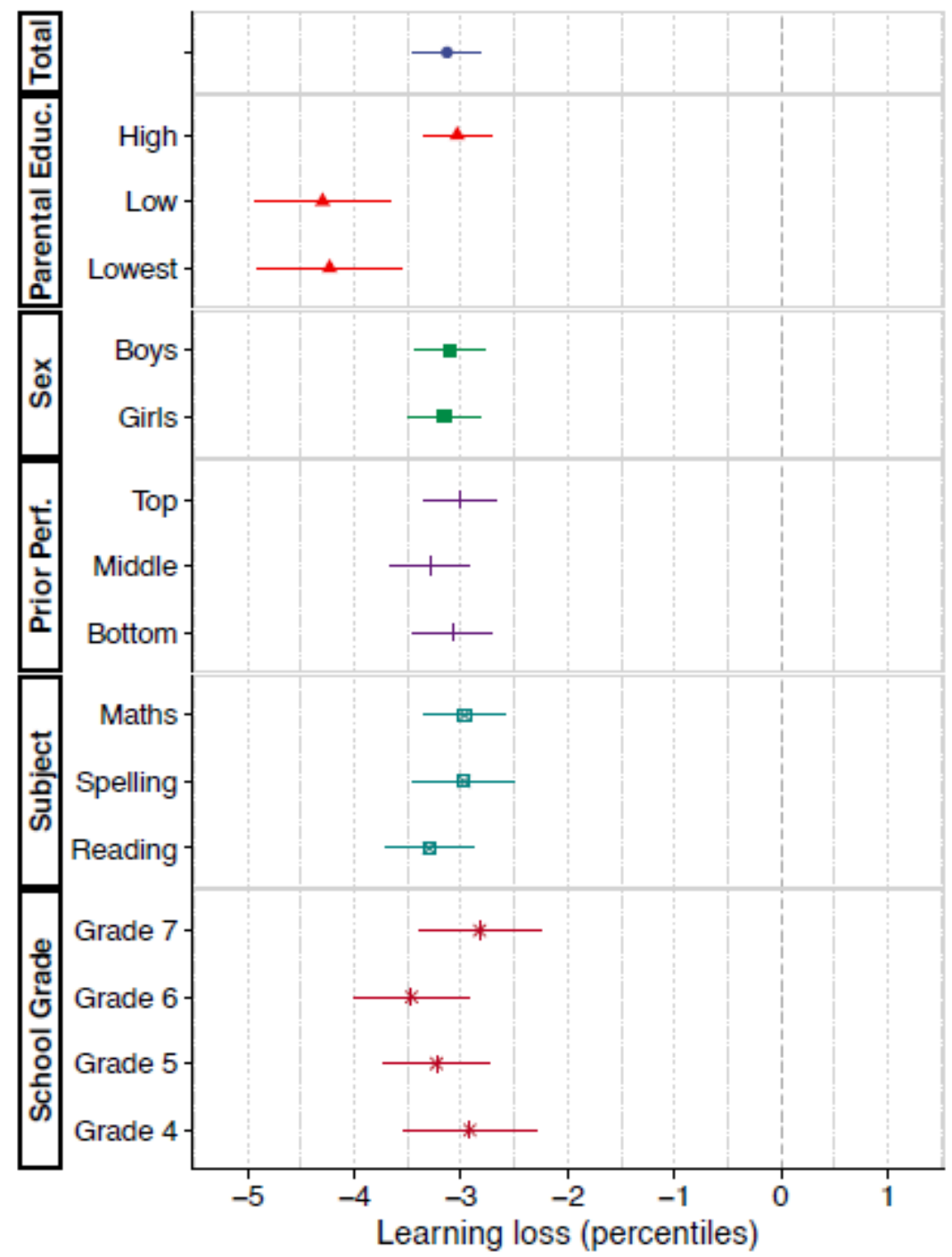

Notes: The graph shows estimates of learning loss from a difference-in-differences specification that compares learning progress between the two testing dates in 2020 to that in the three previous years. Statistical controls include time elapsed between testing dates and a linear trend in year. Point estimates with $95 \%$ confidence intervals, robust standard errors accounting from clustering at the school level. One percentile point corresponds to approximately $2.5 \%$ of a standard deviation. Where not otherwise noted, effects refer to a composite score of math, spelling, and reading. 
Table D.1: Children and school Closures due to COVID-19

\begin{tabular}{cccc}
\hline Country & Authors & Phenomenon & Direction \\
\hline \hline 192 countries & Psacharopoulos et al. (2020) & Loss in earnings & Increase \\
\hline US & Fuchs-Schündeln et al. (2020) & Loss in earnings & Increase \\
\hline US & Fuchs-Schündeln et al. (2020) & High school degree & Decrease \\
\hline DE, AT, CH & Huber and Helm (2020) & Learning & Decrease \\
\hline DE & Grewenig et al. (2021) & Learning & Decrease \\
\hline UK & Andrew et al. (2020) & Learning & Decrease \\
\hline US & Agostinelli et al. (2020) & Learning & Decrease \\
\hline NL & Engzell et al. (2020) & Learning & Decrease \\
\hline BE & Maldonado and De Witte (2021) & Learning & Decrease \\
\hline US & Bacher-Hicks et al. (2021) & Search intensity & Decrease \\
\hline US & Bao et al. (2020) & Reading ability & Decrease \\
\hline DE, AT, CH & Huber and Helm (2020) & Technology & Insufficient \\
\hline UK & Andrew et al. (2020) & Technology & Insufficient \\
\hline IE & Doyle (2020) & Technology & Insufficient \\
\hline
\end{tabular}

Notes: The table summarizes results from a variety of studies on the effects of COVID-19 and school closures on education-related outcomes. 